\title{
Visão Baseada em Recursos: uma ANÁlise bibliométrica DOS ÚLTIMOS 11 ANOS
}

\author{
Resource-Based View: a bibliometric analysis of the last eleven years
}

\section{Henrique César Melo Ribeiro}

Doutorando do Programa de Pós-Graduação em Administração, Universidade Nove de Julho - São Paulo - SP, Brasil.

E-mail: hcmribeiro@gmail.com

\section{Benny Kramer Costa}

Professor do Programa de Pós-Graduação em Administração, Universidade Nove de Julho - São Paulo - SP, Brasil.

E-mail: bennycosta@yahoo.com.br

\section{Sérgio Nunes Muritiba}

Professor do Programa de Pós-Graduação em Administração, Universidade Nove de Julho - São Paulo - SP, Brasil.

E-mail:smuritiba@gmail.com

\section{Geraldo Cardoso de Oliveira Neto}

Doutorando do Programa de Pós-Graduação em Administração, Universidade Nove de Julho - São Paulo - SP, Brasil.

E-mail: geraldo.prod@ig.com.br

\section{Resumo}

O objetivo do presente trabalho foi investigar o perfil das pesquisas e a evolução do tema VBR nos artigos publicados nas Revistas classificadas no Qualis B5 a A1 da Capes, no período de 2000 a 2010. Tratou-se de um estudo de análise bibliométrica, que se destinou a quantificar e analisar a produção científica do tema em questão, utilizando-se também da abordagem quantitativa, além da estatística descritiva. Foram analisados 183 artigos publicados no referido período. Foram utilizadas as seguintes palavras-chave: visão baseada em recursos, vbr, resource based view, rbv, teoria dos recursos e resource based theory. Verificou-se uma área que vem evoluindo em números de artigos publicados e que se caracteriza por estar baseada em teorias consolidadas, a maioria das referências investigadas na pesquisa é dos anos de 2000 a 2003, em particular o ano de 2001. Constatou-se uma evolução da referida temática na literatura acadêmica no contexto brasileiro.

Palavras-chave: VBR. Estratégia. Análise Bibliométrica.

\begin{abstract}
The objective of this study was to investigate the profile of research and RBV development of the theme in the articles published in Journals classified in A1 to B5 Qualis Capes in the period 2000 to 2010. It was a bibliometric analysis study, which was intended to quantify and analyze scientific production on the topic, while also utilizing the quantitative approach, and descriptive statistics. We analyzed 183 articles published in that period. We used the following keywords: visão baseada em recursos, vbr, resource based view, rbv, teoria dos recursos e resource based theory. There was an area that is evolving in numbers published articles and which is characterized by being based on theories consolidated most of the references is investigated in the research of years 2000 to 2003, particularly 2001. There was an evolution of that theme in the academic literature in Brazilian context.
\end{abstract}

Key words: RBV. Strategy. Bibliometric Analysis. 


\section{INTRODUÇÃO}

Várias correntes de pensamento surgem, aplicando-se nas empresas e sendo embasadas por várias teorias, como: teoria da agência (JENSEN; MECKLING, 1976); teoria evolucionária (NELSON; WINTER, 1982); teoria de custos de transação (WILLIAMSON, 1985); teoria do posicionamento no mercado (PORTER, 1980, 1985); teoria institucional (ZUCKER, 1987); teoria da aprendizagem organizacional (LEVITT; MARCH, 1988); teoria da contingência (BOYD, 1995); e o Resource-Based View - RBV (BARNEY, 1991). A $\mathrm{RBV}$ é uma teoria que se desenvolveu mediante as ideias de Penrose, Wernerfelt e Barney, seguindo-se a esses Peteraf e, a posteriori de Collis e Montgomery, dentre outros. (ARAGÃO et al., 2010)

Diante disso, ressalta-se que a Teoria Baseada em Recursos foca prioritariamente as condições internas às firmas, como responsáveis pelo desempenho superior, ou seja, pela abordagem da RBV, percebe-se que ela se fundamenta na administração de recursos tangíveis e intangíveis, na heterogeneidade das empresas, e nas variáveis que impactam na dinâmica setorial e criam vantagem competitiva para certas firmas (BARNEY, 1991), sendo que na perspectiva da RBV, pode ocorrer vantagem competitiva de duas formas, pelo posicionamento (WERNERFELT, 1984) e pela sustentabilidade. (DIERICKX; COOL, 1989)

Diante do exposto, constata-se que a discussão conceitual e publicações internacionais sobre RBV só iniciaram-se nos anos de 1980, porém, somente em 1990 tal abordagem passou a ser estudada e veiculada em periódicos e eventos nacionais. Exemplo disso é a publicação dos autores Carneiro et al. (1997), os quais contemplaram a temática em seu artigo da RAE, conceituando-a como uma teoria estratégica baseada em recursos e competências da empresa. Salientaram também que o referido tema, estava ainda em desenvolvimento, mas que vinha ganhando gradual aceitação no meio acadêmico.

Com uma defasagem de 12 anos, o estudo de Serra et al. (2008), nos deu uma noção da evolução do tema RBV no Brasil, ao analisar os trabalhos selecionados e apresentados no EnANPAD de 1997 a 2006. E mais recentemente os autores Aragão et al. (2010), analisaram no período também de 1997 a 2006, os congressos do EnANPAD, 3Es e EMA e as revistas
RAC, RAE e RAUSP. Tais publicações evidenciaram uma noção da evolução dos estudos da RBV em âmbito nacional. Porém, constata-se que em ambos os estudos foram trabalhados os EnANPADs de 1997 a 2006 e no estudo de Aragão et al. (2010), poucas revistas, apesar delas serem os principais periódicos de administração no Brasil. Além disso, nas duas pesquisas, foram estudadas as publicações até 2006 , o que retrata uma defasagem de quatro anos em publicações sobre o assunto até este momento.

Dessa forma, é importante existir uma investigação mais atual da difusão da temática da Visão Baseada em Recursos (VBR) nas produções científicas, visando desencadear futuros trabalhos correlatos e ou que envolvam esse tema. De acordo com o aporte teórico, constata-se que existem outros estudos de cunho bibliométrico envolvendo o assunto VBR, porém, espera-se nesta pesquisa avançar no assunto, apresentando um panorama das publicações nas revistas Qualis B5 a A1 (triênio 2007-2009), entre os anos de 2000 a 2010, demonstrando a importância e a emergência da temática para os atuais e futuros pesquisadores.

Em relação aos pesquisadores, o referido trabalho em linhas gerais pode ser útil para melhor compreensão da temática da VBR e sua evolução como um campo emergente de estudos, revelando todas as nuances, vitalidade e o crescimento dessa temática, proporcionando assim outras possibilidades de maior compreensão e desenvolvimento de pesquisas futuras.

Diante desse contexto, evidencia-se uma pergunta que fundamenta as linhas mestras deste estudo, ou seja, qual é o perfil das pesquisas e a evolução do tema VBR nos artigos publicados nas Revistas classificadas no Qualis B5 a A1 da Capes, no período de 2000 a 2010? Diante do exposto tem-se como objetivo geral: Investigar o perfil das pesquisas e a evolução do tema VBR nos artigos publicados nas Revistas classificadas no Qualis B5 a A1 da Capes, no período de 2000 a 2010.

Este artigo se divide em cinco partes. A primeira contempla a introdução. A segunda parte é a revisão da literatura, a qual busca evidenciar a introdução e a evolução da temática VBR na estratégia e na literatura acadêmica por meio de pesquisas bibliométricas. $\mathrm{O}$ método de pesquisa empregado na pesquisa é explicitado na parte três. A quarta parte aborda a análise e discussão dos resultados, confrontando-as com a 
revisão da literatura. Finalmente, na parte cinco, são realizadas as considerações finais.

\section{Revisão da Literatura}

Esta seção apresenta uma introdução e evolução do tema Visão Baseada em Recursos ao longo das últimas décadas e os estudos nacionais desenvolvidos sobre a produção acadêmica sobre a temática.

\subsection{Visão Baseada em Recursos: introdução e evolução}

A RBV fundamenta-se nos trabalhos da economista Edith Penrose nos anos de 1950 (BERTERO et al., 2003), por ela embasar a abordagem teórica da temática (JÚNIOR et al., 2009), ou seja, segundo Mintzberg (2000), a autora trouxe à tona o argumento de que a singularidade provê a base para o crescimento empresarial, de maneira que ao criar produtos únicos, singulares, as organizações também desenvolvem capacidades e recursos únicos.

Porém, no início da década de 1980, o trabalho de Penrose (1959) recebeu contribuições relevantes, com os primeiros estudos abordando o tema RBV, por meio de vários autores como Lippman e Rumelt (1982), que evidenciaram os conceitos de ambiguidade causal; Wernerfelt (1984), que desenvolveu trabalhos de vantagem competitiva posicional dos recursos; Rumelt (1984), que contemplou os conceitos de isolamento de recursos; Dierickx e Cool (1989), que abordou conceitos de vantagem competitiva sustentável e focando suas análises nas barreiras à imitação; e Hamel e Prahalad (1994), que deram uma contribuição no final da década de 1980 para a construção do conceito de "competências essências" (core competence).

Constata-se assim que as competências essenciais seriam a capacidade de integrar recursos e produtos e serviços, ou seja, a competitividade de uma empresa seria determinada pelo alinhamento entre as competências da empresa e a sua estratégia formulada e adotada de maneira a gerar vantagem competitiva. Nesse instante, verifica-se um link da core competence e a RBV, evidenciada em linguagem acessível aos executivos; entre vários outros. (SERRA et al., 2008)
Na década de 1990, surge uma nova abordagem, resgatando o âmbito interno da organização, ou seja, sustentado que o resultado superior, ou a vantagem competitiva, se relaciona a diferenças internas entre empresas (TONDOLO; BITENCOURT, 2008), sendo considerada por Barney (1991), a abordagem mais consistente para determinar vantagem competitiva sustentável entre organizações.

Nesse contexto, a abordagem da RBV torna-se paradigma dominante na pesquisa de conteúdo estratégico (RIVERA, 2008), embasada segundo Wernerfelt (1984), Dierickx e Cool (1989) e Barney (1991), na questão-chave da análise, isto é, a gestão de recursos tangíveis e intangíveis, na heterogeneidade das empresas e como essas variáveis impactam na dinâmica do setor, criando vantagem competitiva posicional $e$ sustentável para diferentes organizações. Para Barney (1991), na linguagem da análise estratégica tradicional, os recursos da firma são forças que as empresas podem conceber e implementar suas estratégias.

Diante do cenário, Lippman e Rumelt (1982), Rumelt (1984), Dierickx e Cool (1989) e Barney (1991) afirmam que os recursos precisam ser valiosos para explorar as oportunidades e ou minimizar as ameaças do ambiente externo; raros e não disponíveis a outros concorrentes; imperfeitamente imitáveis ou inimitáveis, na medida em que dependem de desenvolvimentos empresariais e são protegidos pela ambiguidade causal; e insubstituíveis, ou seja, não poderão existir recursos idênticos que permitam replicar um resultado semelhante.

Porém, as empresas não podem obter vantagem competitiva sustentável se os recursos empregados estão disponíveis a todas as empresas ou possuem alta mobilidade (BINDER, 2009). No entanto, diversos fatores podem estar ligados à raridade e à dificuldade de imitação dos recursos. Dentre eles encontram-se os de ordem natural (relevo, raridade de recursos minerais, localização), mecanismos legais e institucionais (marcas, patentes, reserva de mercado), além de fatores econômicos ligados às imperfeições do mercado $e$ elementos organizacionais. (BRITO; VASCONCELOS, 2004)

Portanto, entende-se com isso que a fonte principal de vantagem competitiva sustentável são os recursos desenvolvidos e controlados pelas empresas, 
enquanto que outros fatores possuem, para a temática da VBR, importância secundária (COELHO et al., 2009). Diante disso, constata-se que os recursos, sendo eles, tangíveis ou intangíveis, direcionam a empresa à obtenção da vantagem competitiva sustentável aliada às oportunidades do cenário dos negócios.

\subsection{Visão Baseada em Recursos: pesquisas bibliométricas}

Os trabalhos bibliométricos de publicações sobre VBR têm sido desenvolvidas no âmbito nacional. Tal constatação deu-se em virtude das buscas destas publicações para melhor fomento da referida pesquisa, no que se refere à comparação das informações destas com as informações geradas por outras pesquisas correlatas. Diante disso, ressalta-se, a seguir, alguns trabalhos e seus aspectos relevantes, que de maneira preponderante auxiliaram esta pesquisa quanto à compreensão do que já foi realizado sobre a temática da VBR.

Os autores Acedo et al. (2006), tiveram como objetivo analisar de maneira empírica os pressupostos subjacentes da Teoria da RBV sob uma ótica indutiva. Dentre as principais conclusões encontra-se a ligação da RBT (Resource-Based Theory) com a abordagem de outras teorias nos estudos organizacionais e que três principais tendências são descritas e coexistem dentro da RBT, são elas: a VBR, a Visão Baseada no Conhecimento e a Visão Relacional.

Já os autores Serra et al. (2007), tiveram como objetivo verificar a contribuição brasileira nos estudos de estratégia com o enfoque na RBV. Concluiu-se ser importante propor a partir da evolução dos trabalhos nacionais sobre $\mathrm{RBV}$, uma agenda que possa orientar futuras pesquisas.

Constata-se que outro trabalho dos autores Serra et al. (2008), agora com a inclusão do autor Lissoni é similar à publicação anteriormente evidenciada. Dentre as conclusões, constatou-se que é evidente o peso dos estudos de caso, com o crescimento relativo dos artigos empíricos em relação aos artigos puramente técnicos. Verificou-se também a existência de grupos de pesquisa em RBV, possibilitando assim o crescimento da temática e uma cooperação maior entre os pesquisadores.

Walter e Silva (2008) fizeram um estudo com o objetivo de analisar como a VBR estava sendo estuda- da na área de estratégia do EnANPAD e, por meio da análise de redes sociais, pretendiam verificar se existia associação entre autores e instituições nesses estudos. Concluiu-se que as análises de redes sociais demonstram que a cooperação entre autores e instituições que utilizam a abordagem VBR na área de estratégia do EnANPAD ainda é restrita.

Evidencia-se o trabalho dos autores Walter et al. (2008), o qual objetivou analisar os delineamentos metodológicos e a adequação destes às exigências metodológicas dos artigos que investigaram a abordagem VBR, publicados na área de estratégia do EnANPAD de 1997 a 2007. O referido estudo concluiu que: um predomínio dos estudos de caso com aproximadamente $56,4 \%$ dos estudos e que a abordagem VBR encontra-se com relativa maturidade.

Os autores Júnior et al. (2009), tiveram como objetivo caracterizar que tipo de contribuição a VBR pode trazer para a pesquisa em Contabilidade Gerencial, além de levantar os principais autores, instituições, países e veículos de publicação nos quais são realizadas e publicadas as pesquisas sobre RBV. Foi constatada a existência de uma concentração da pesquisa em RBV nas universidades dos Estados Unidos, principalmente, devido ao elevado número de citações dos trabalhos desenvolvidos por Jay B. Barney.

Outro trabalho interessante foi dos autores Coelho et al. (2009), a referida pesquisa teve como objetivo identificar a contribuição da VBR nos estudos organizacionais contemporâneos em produções científicas, analisando a disseminação e a comparabilidade entre os trabalhos publicados nacionais e internacionais. Concluiu-se no estudo que existe uma crescente difusão da VBR, em sua maioria, no cenário internacional.

Por fim, o estudo dos autores Aragão et al. (2010) tive o objetivo de levantar a produção científica dos temas VBR e Capacidades Dinâmicas no país. Concluiu-se que a maioria dos trabalhos possui abordagens qualitativas, com preferência pelo uso de estudo de caso. Constatou-se também que o referencial teórico carece de renovação.

Essas pesquisas comprovaram que a VBR é um assunto emergente e se encontra em relativa maturidade no Brasil, porém, ele vem sendo estudado com uma consistência maior nos últimos anos, razão pela qual se constata o crescimento e o fomento de pesquisas científicas e da literatura acadêmica sobre a temática. 


\section{Método de Pesquisa}

Este estudo tem por objetivo mapear a produção científica sobre RBV em periódicos brasileiros, ou seja, investigar o perfil das pesquisas e a evolução do tema VBR nos artigos publicados nas Revistas Brasileiras classificadas pelo sistema CAPES como Qualis B5 a A1, no período de 2000 a 2010. Assim, trata-se de um estudo de análise bibliométrica, que se destina a quantificar e analisar a produção científica do tema. (COOPER; LINDSAY, 1998)

Para Leite Filho (2006), indicadores de performance bibliométrica são importantes para avaliar a pesquisa acadêmica, nortear rumos e estratégias de futuras pesquisas. O planejamento de uma pesquisa de análise bibliométrica passa por quatro etapas importantes adicionais à etapa de formulação do problema de pesquisa: a escolha da literatura analisada, a avaliação dos dados coletados, a análise e interpretação das informações e a apresentação dos resultados. (COOPER; LINDSAY, 1998)

Salienta-se que a bibliometria desenvolveu-se mediante a elaboração de leis empíricas sobre o comportamento da literatura (ARAÚJO, 2006). Nesse cenário, é importante conhecer as três leis básicas da bibliometria, para o melhor entendimento dos dados (Quadro 1). Remete-se que tais Leis são oriundas respectivamente de três pesquisadores que se destacam por suas importantes descobertas Bradford, Zipf e Lotka (VANTI, 2002), sendo assim, as mais comumente utilizadas e relacionadas à produtividade científica. (BUFREM; PRATES, 2005)

Salienta-se que a esse grupo de leis agregaram-se, a posteriori, outros estudos que configuram o corpo das preocupações dos pesquisadores da informação, a saber: Lei de Goffmam; a Frente de Pesquisa ou Elitismo; e a Obsolescência/Vida média/Idade da literatura. (ALVARADO, 1984)

A escolha de qual a literatura que será analisada é um dos pontos-chave de análises do gênero, pois define o escopo do estudo e pode impactar sua validade (SINGLETON; STRAITS, 1999). Neste estudo, como se pretendia analisar a produção nacional sobre o tema, foi escolhida uma amostra de periódicos nacionais relevantes. A relevância foi dada pela classificação dos periódicos na lista Qualis, da Coordenação de Aperfeiçoamento de Pessoal no Nível Superior (CAPES).

\begin{tabular}{|c|c|}
\hline LEIS & DEFINIÇÃo \\
\hline $\begin{array}{l}\text { Bradford } \\
\text { ou } \\
\text { Dispersão }\end{array}$ & $\begin{array}{l}\text { Mensura o nível de atração dos (QUONIAM et al., } \\
\text { periódicos sobre determinado } 2001 ; \text { MORETTI; } \\
\text { tema } \\
\begin{array}{ll}\text { CAMPANARIO, } \\
\text { 2009; PINTO } \\
\text { et al., 2010) }\end{array}\end{array}$ \\
\hline $\begin{array}{l}\text { Lotka ou } \\
\text { Quadrado } \\
\text { Inverso }\end{array}$ & $\begin{array}{l}\text { Evidencia a produtividade (e (VANTI, 2002; } \\
\text { citações) de autores por meio CARDOSO et al., } \\
\text { de um modelo de distribuição 2005; MORETT; } \\
\text { de tamanho-frequência em CAMPANARIO, } \\
\text { um conjunto de publicações, 2009; GAZDA; } \\
\text { concentrando-se assim em QUANDT, 2010) } \\
\text { aspectos de coautoria. }\end{array}$ \\
\hline $\begin{array}{l}\text { Zipf ou } \\
\text { Mínimo } \\
\text { Esforço }\end{array}$ & $\begin{array}{l}\text { Mensura a quantidade de (QUONIAM } \\
\text { ocorrências das palavras em et al., 2001; } \\
\text { vários textos, gerando uma lista VANTI, 2002; } \\
\text { de termos de uma determinada CARDOSO et al., } \\
\text { temática sendo utilizada para 2005; MORETTI; } \\
\text { observar qual tema científico é CAMPANARIO, } \\
\text { tratado nos artigos. }\end{array}$ \\
\hline
\end{tabular}

Quadro 1: Leis da bibliometria

Fonte: Elaborado pelos autores deste artigo

A CAPES (2006) é um órgão ligado ao Ministério da Educação, criado em 1951 com o objetivo de "[...] assegurar a existência de pessoal especializado em quantidade e qualidade suficientes para atender às necessidades dos empreendimentos públicos e privados que visam ao desenvolvimento do país". Atualmente, a CAPES é responsável pelo reconhecimento e avaliação da qualidade dos cursos de pós-graduação no país.

Como forma de analisar a produção científica dos programas de Mestrado e Doutorado no país, o órgão classifica os periódicos e os congressos nacionais e internacionais de acordo com sua relevância para a Administração. É divulgada então a listagem conhecida como Qualis,

[...] uma lista de veículos utilizados para a divulgação da produção intelectual dos programas de pós-graduação stricto sensu (mestrado e doutorado), classificados quanto ao âmbito de circulação (Local, Nacional, Internacional) e à qualidade $(\mathrm{A}, \mathrm{B}, \mathrm{C})$, por área de avaliação. (CAPES, 2011)

Foram escolhidos os periódicos classificados com a nota A1, A2, B1, B2, B3, B4 e B5 pela Qualis da Área de Administração (triênio 2007-2009), que representa o extrato superior de avaliação. Dentre os periódicos 
evidenciados, a amostra descreve aqueles que, pela temática, podem conter estudos de RBV. Dessa forma, chegou-se à relação contemplada no Quadro 2.

\begin{tabular}{|c|c|c|c|c|}
\hline Título do Periódico & SIGLA* & ISSN & Categoria & Nota \\
\hline Brazilian Administration Review & BAR & $1807-7692$ & Nacional & A2 \\
\hline Revista de Administração Pública & RAP & 0034-7612 & Nacional & A2 \\
\hline Cadernos EBAPE & EBAPE & $1679-3951$ & Nacional & B1 \\
\hline Revista de Administração Contemporânea & $\mathrm{RAC}$ & $1415-6555$ & Nacional & B1 \\
\hline RAC-Eletrônica & RAC-e & $1981-5700$ & Nacional & B1 \\
\hline Revista de Administração de Empresas & RAE & $0034-7590$ & Nacional & B1 \\
\hline RAE-Eletrônica & RAE-e & $1676-5648$ & Nacional & B1 \\
\hline Revista de Administração Mackenzie & RAM & $1518-6776$ & Nacional & B1 \\
\hline Brazilian Business Review & BBR & $1807-734 x$ & Nacional & B2 \\
\hline Revista de Administração da USP & RAUSP & 0080-2107 & Nacional & B2 \\
\hline RAUSP-Eletrônica & RAUSP-e & $1983-7488$ & Nacional & B2 \\
\hline Revista Eletrônica de Administração & READ & $1413-2311$ & Nacional & B2 \\
\hline Revista BASE & BASE & $1807-054 x$ & Nacional & B2 \\
\hline Revista de Administração & FACES & $1517-8900$ & Nacional & B3 \\
\hline Gestão \& Planejamento (Salvador) & G\&P & $1516-9103$ & Nacional & B3 \\
\hline Gestão.Org & GESTÃO & $1679-1827$ & Nacional & B3 \\
\hline Revista de Administração e Inovação & RAI & 1809-2039 & Nacional & B3 \\
\hline Revista de Gestão USP & REGE & $1809-2276$ & Nacional & B3 \\
\hline Revista Brasileira de Gestão de Negócios & RBGN & $1806-4892$ & Nacional & B3 \\
\hline Revista Brasileira de Gestão de Negócios & RBGN-e & 1983-0807 & Nacional & B3 \\
\hline Revista Brasileira de Inovação & $\mathrm{RBI}$ & $1677-2504$ & Nacional & B3 \\
\hline Revista de Ciências da Administração & CAD & $1516-3865$ & Nacional & B3 \\
\hline Revista de Gestão USP - (até 2005) & REGE & $1516-7747$ & Nacional & B3 \\
\hline Revista de Negócios (Online) & RN-e & $1980-4431$ & Nacional & B3 \\
\hline Análise (PUCRS) & Análise-PUC & $1516-2680$ & Nacional & B4 \\
\hline Análise (UFRGS. 2006) & Análise-UFRGS & $1980-6302$ & Nacional & B4 \\
\hline Contextus (Fortaleza) & Contextus & $1678-2089$ & Nacional & B4 \\
\hline Revista ANGRAD & ANGRAD & $1518-5532$ & Nacional & B4 \\
\hline Revista Ciências Administrativas (UNIFOR) & $\mathrm{RCA}$ & $1414-0896$ & Nacional & B4 \\
\hline Revista da FAE & FAE & $1516-1234$ & Nacional & B4 \\
\hline Revista de Administração da FEAD-Minas & FEAD & $1807-1937$ & Nacional & B4 \\
\hline Revista de Economia e Administração & REA & $1676-7608$ & Nacional & B4 \\
\hline Adm. MADE (Universidade Estácio de Sá) & MADE & $1518-9929$ & Nacional & B5 \\
\hline Cadernos da FCECA (PUCCAMP) & FCECA & 0104-1495 & Nacional & B5 \\
\hline Gestão e Desenvolvimento (FEEVALE) & GED & $1807-5436$ & Nacional & B5 \\
\hline Revista Eletrônica de Ciência Administrativa & RECADM & $1677-7387$ & Nacional & B5 \\
\hline Revista de administração da Unimep & RAU & $1679-5350$ & Nacional & B5 \\
\hline Revista de Ciências Gerenciais & RCG & $1415-6571$ & Nacional & B5 \\
\hline Revista Gerenciais (Uninove) & RG & $1677-2768$ & Nacional & B5 \\
\hline
\end{tabular}

Nota: A maioria das revistas tem a sua sigla, para algumas foram criadas siglas para serem utilizadas em gráficos e quadros

Quadro 2: Classificação das revistas

Fonte: Capes (2011) 
O Quadro 2 mostra, portanto, que neste estudo foram analisadas 39 revistas científicas nacionais. A coleta de dados foi feita buscando, nessas revistas, artigos publicados entre 2000 e 2010. Cada um dos periódicos passou por um processo de busca de artigos que correspondeu à temática deste estudo. Tal busca, foi realizada eletronicamente, nas bases Scielo, Google Acadêmico e nos sites respectivos de cada Revista.

O critério utilizado para a seleção dos artigos foi baseado na ocorrência das terminologias empregadas para identificar as abordagens da VBR, conforme localizadas não simultaneamente no título, no resumo, nas palavras-chave, na fundamentação teórica e ou nas referências bibliográficas dos artigos deste estudo. Constata-se, também que para selecionar os artigos relevantes, foram utilizadas as seguintes palavras-chave, não simultaneamente: visão baseada em recursos, vbr, resource based view, rbv, teoria dos recursos e resource based theory. Ressalta-se que não foram usadas as palavras-chave simultaneamente, de forma que foram selecionados todos os artigos que tinham ao menos uma das palavras mencionadas anteriormente.

Após a escolha dos artigos, estes foram catalogados utilizando-se o software Mendeley Desktop, que organiza referências bibliográficas. Eles também foram analisados conforme os seguintes indicadores: Evolução do tema; Periódicos de destaque; Características de autoria; Autores com maior produção neste tema; Autores mais citadas; Abordagens metodológicas; e Referências por período. A análise dos indicadores foi feita de forma quantitativa, utilizando-se estatística descritiva para os indicadores anteriormente mencionados. Os resultados estão apresentados no item a seguir.

Ressalta-se que para fomentar a análise das características de autoria, empregou-se a análise de redes sociais mediante o software UCINET 6 for Windows (versão 6.357). Tal ação se deu por entender que o conhecimento científico é construído socialmente (ROSSONI; HOCAYEN-DA-SILVA, 2008), influenciado pelos pesquisadores e seus pares que compõem estruturalmente a rede de relações entre as Instituições de Ensino Superior (ROSSONI et al., 2008). Entende-se também que a relação entre os pesquisadores se correlacionam com a produção do conhecimento científico em um campo de conhecimento. (ROSSONI; HOCAYEN-DA-SILVA, 2008)

\section{Análise e Discussão dos Resultados}

A finalidade deste capítulo foi mobilizar a análise bibliométrica dos 183 artigos publicados nas Revistas Qualis B5 a A1. Para tanto, foi subdivida a análise dos resultados em seis tópicos, como segue: (I) evolução do tema e periódicos de destaque; (II) características de autoria; (III) autores com maior produção neste tema; (IV) referências mais citadas; (V) referências por período; (VI) abordagens metodológicas.

\subsection{Evolução do Tema e Periódicos de destaque}

O Gráfico 1 evidencia o número de artigos publicados sobre o tema VBR, como tema central ou secundário no período analisado.

Ao analisar o Gráfico 1, ressalta-se que a pouca ocorrência de estudos relacionados à temática nos anos de 2000 e 2001. Porém, houve um aumento substancialmente sobre o tema a partir de 2002, apresentando uma evolução do percentual aproximado de $500 \%$ deste ano para 2010. Corroboram em parte com a afirmação os autores Walter e Silva (2008), ao afirmarem que as publicações sobre o tema vêm crescendo de 1999 até 2007, limite da referida pesquisa.

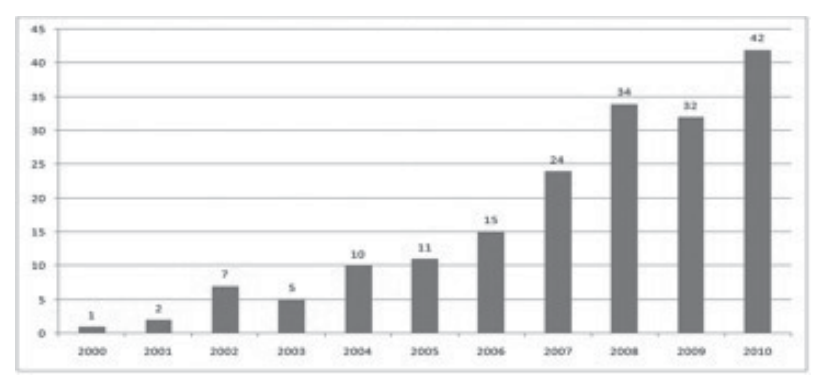

Gráfico 1: Evolução dos artigos por ano

Fonte: Dados da pesquisa

Uma provável explicação para tal fenômeno foram as publicações de âmbito internacional consolidadas e que tiveram uma forte influência na construção da teoria da RBV que precederam esses períodos e que de alguma forma impactaram diretamente e ou indiretamente no fomento (impulsão) de novas pesquisas sobre o assunto no âmbito internacional e nacional.

Tais publicações seriam: Penrose (1959), Lippman e Rumelt (1982), Wernerfelt (1984), Rumelt (1984), Dierickx e Cool (1989), Barney (1991), Peteraf 
(1993), Hamel e Prahalad (1994), Teece et al. (1997), Barney (2001), Priem e Butler (2001), Barney, Wright e Jr. Ketchen (2001) e Helfat e Peteraf (2003). Pode-se citar também, de acordo com Acedo et al. (2006), os autores Makadok et al. (2006) e Phelan e Lewin como responsáveis por essa evolução.

Esses tipos de pesquisa, mediante seus autores, são muito importantes para esclarecer as ideias centrais que sustentam a teoria da RBV, facilitando assim o máximo retorno possível de esforços de investigação (ACEDO et al. 2006). Ainda segundo os autores, os resultados dessas pesquisas mostram um crescimento exponencial do número de trabalhos publicados que utilizam abordagem RBT no período por eles pesquisados.

Podem se destacar também as primeiras publicações sobre o tema VBR no âmbito nacional, pois, de certa forma, elas também foram importantes para a disseminação e o crescimento da temática no Brasil, seriam: Carneiro et al. (1997), Lopes e Reinhard (1998), Vasconcelos e Cyrino (2000), Fleury e Fleury (2001), Wilk (2001) e Nassif e Hanashiro (2002). Entende-se então, que as publicações sobre o tema em questão vêm crescendo de maneira constante, proporcionando uma consolidação e uma maturidade deste, influenciando diretamente no interesse de novos pesquisadores e a posteriori no fomento de sua literatura na academia.

A análise do Gráfico 2 das principais revistas Qualis deste estudo evidencia uma hierarquia na qual está publicada a maior parte dos artigos sobre VBR sendo como tema central ou não. Observa-se que mais da metade, ou seja, $56,83 \%$ dos artigos publicados estão contemplados nas revistas: RAC, BAR, RAI, BASE e RAE.

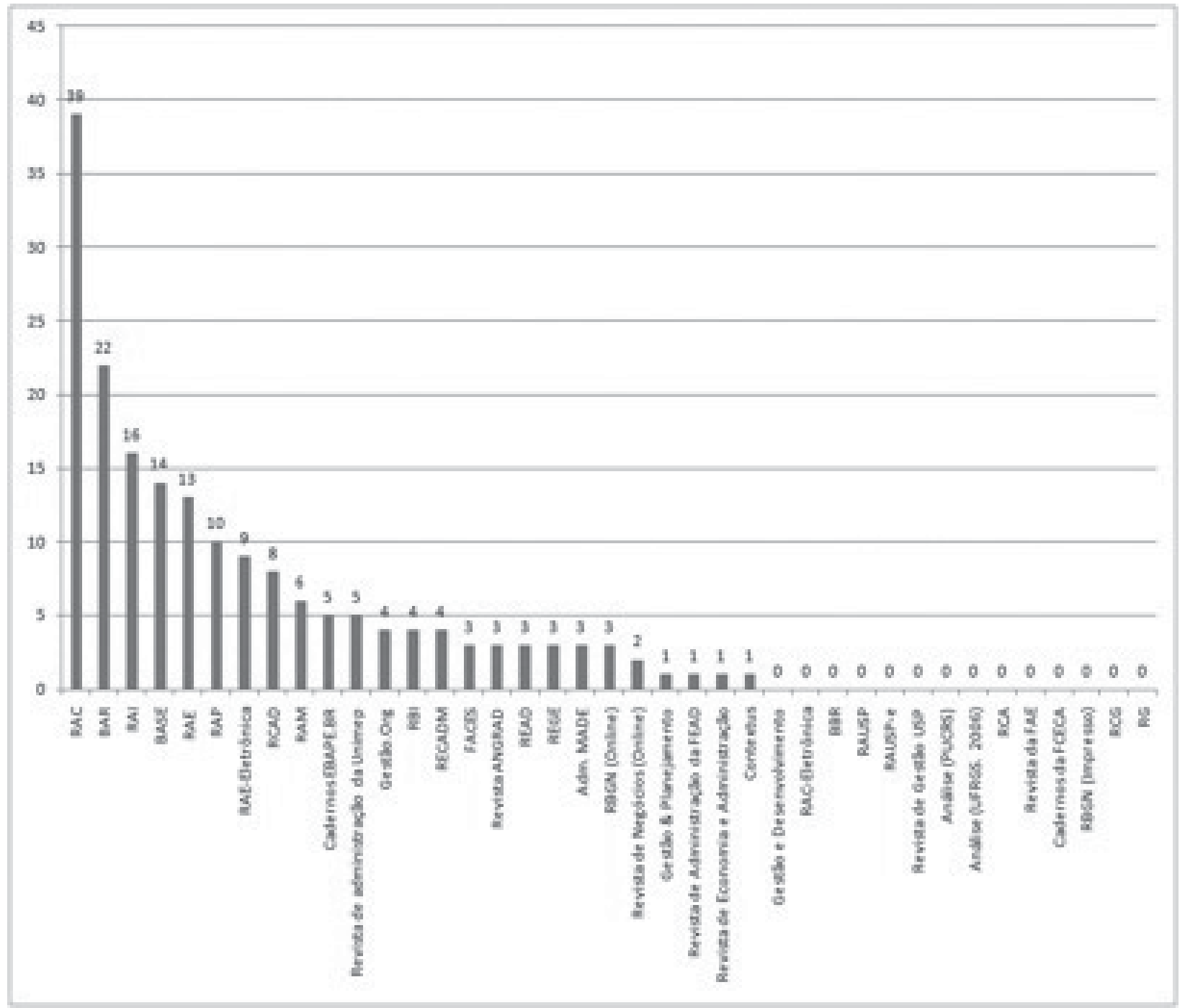

Gráfico 2: Número de artigos por revista

Fonte: Dados da pesquisa 
Diante do cenário, a Lei de Bradford vai de encontro ao que foi contemplado no Gráfico 2, pois, está lei reporta-se à dispersão dos periódicos científicos, evidenciando seus respectivos graus de relevância na literatura acadêmica. Bradford compreendeu que um núcleo essencial de revistas forma a base da literatura para todas as disciplinas, e que, portanto, a maioria dos trabalhos importantes é publicada em poucas revistas (TESTA, 1998), sendo considerados assim periódicos de maior fator de impacto.

Assim, ordenando os 39 periódicos investigados em ordem de produtividade decrescente de relevância da temática VBR, três zonas vão aparecer, ou seja, a primeira zona contendo um pequeno número de periódicos altamente produtivos (RAC, BAR, RAI, BASE $e$ $\mathrm{RAE})$, a segunda contemplando um número maior de revistas menos produtivas (RAP, RAE-e, RCAD, RAM, Cadernos Ebape, RAU, Gestão.org, RBI e RECADM) e a terceira e última, incluindo mais periódicos ainda, mas cada um com ainda menos produtividade sobre a temática ora estudada (demais revistas).

\subsection{Características de Autoria}

O número de autores que publicam cada artigo evidencia redes e parcerias entre autores. Na medida em que mais autores publicam em conjunto, percebe-se que a área é investigada por grupos de pesquisa ao invés de autores individuais. A colaboração entre autores vem sendo vista internacionalmente como um dos indicadores de qualidade da pesquisa, principalmente em temas interdisciplinares (SUBRAMANYAM, 1983), como é o caso da VBR.
O Gráfico 3 apresenta a frequência de artigos de autoria individual e com mais autores por artigo. No que se refere ao Gráfico 3, verifica-se que os artigos individuais ocorrem em menor número em comparação com a soma dos artigos de 2 ou mais autores, podendo ser um indicativo da existência de grupos de pesquisa sobre a temática.

Como pode ser observado, prevalece o número de artigos publicados com dois autores, representando aproximadamente $52 \%$ e com três autores com cerca de $21 \%$ da amostra. Os autores Coelho et al. (2009) corroboram com as informações ao afirmarem em sua pesquisa que a maioria dos autores tem suas publicações envolvendo três e dois autores, respectivamente.

\subsection{Autores com maior Produção Neste Tema}

A análise dos autores que mais publicam em determinado assunto revela, primeiramente, a maturidade da área. Áreas mais maduras tendem a ter pesquisadores com histórico de pesquisa relevante. (NEDERHOF, 2006)

O Gráfico 4 contempla o nome de Flávio Carvalho de Vasconcelos como o autor que mais publica artigos sobre VBR no período analisado, ou seja, nove publicações. Tal afirmação é corroborada e confirmada pelos autores Aragão et al. (2010) e Walter e Silva (2008) em suas respectivas pesquisas. Em seguida, são evidenciados os autores Luiz Artur Ledur Brito e Teresia Diana L.V.A. de Macedo-Soares, com oito e sete artigos publicados respectivamente.

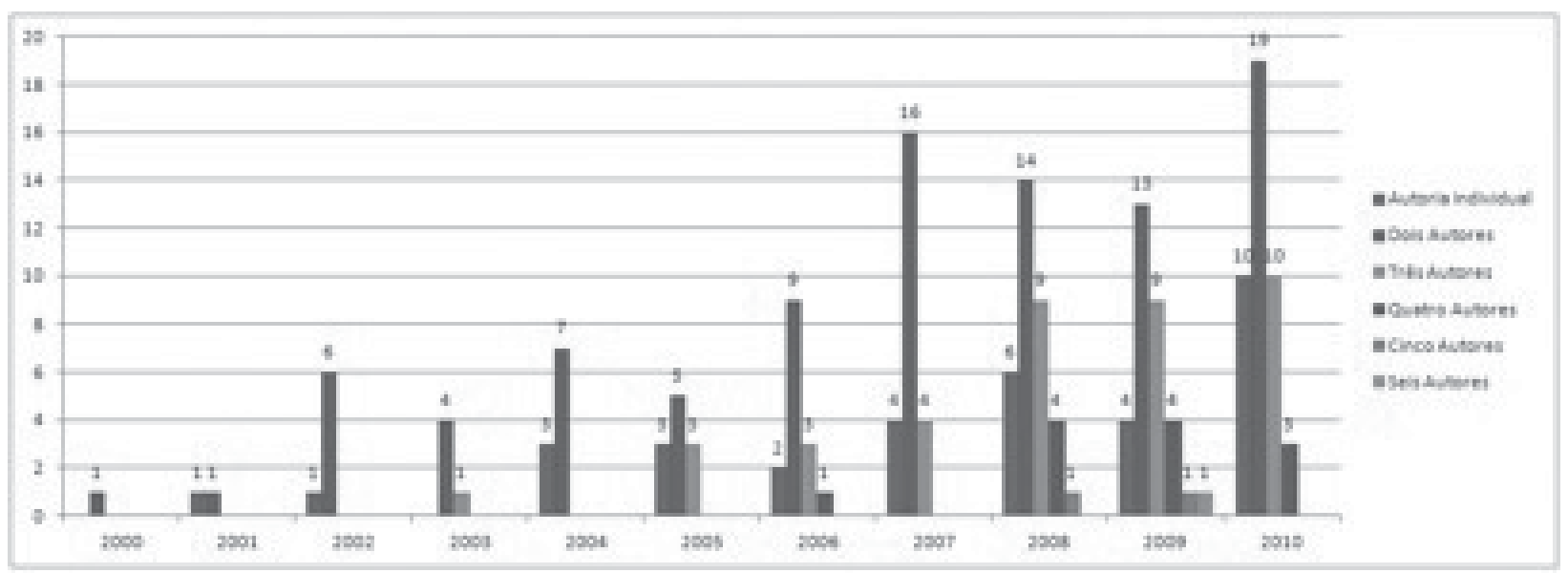

Gráfico 3: Autoria dos artigos

Fonte: Dados da pesquisa 


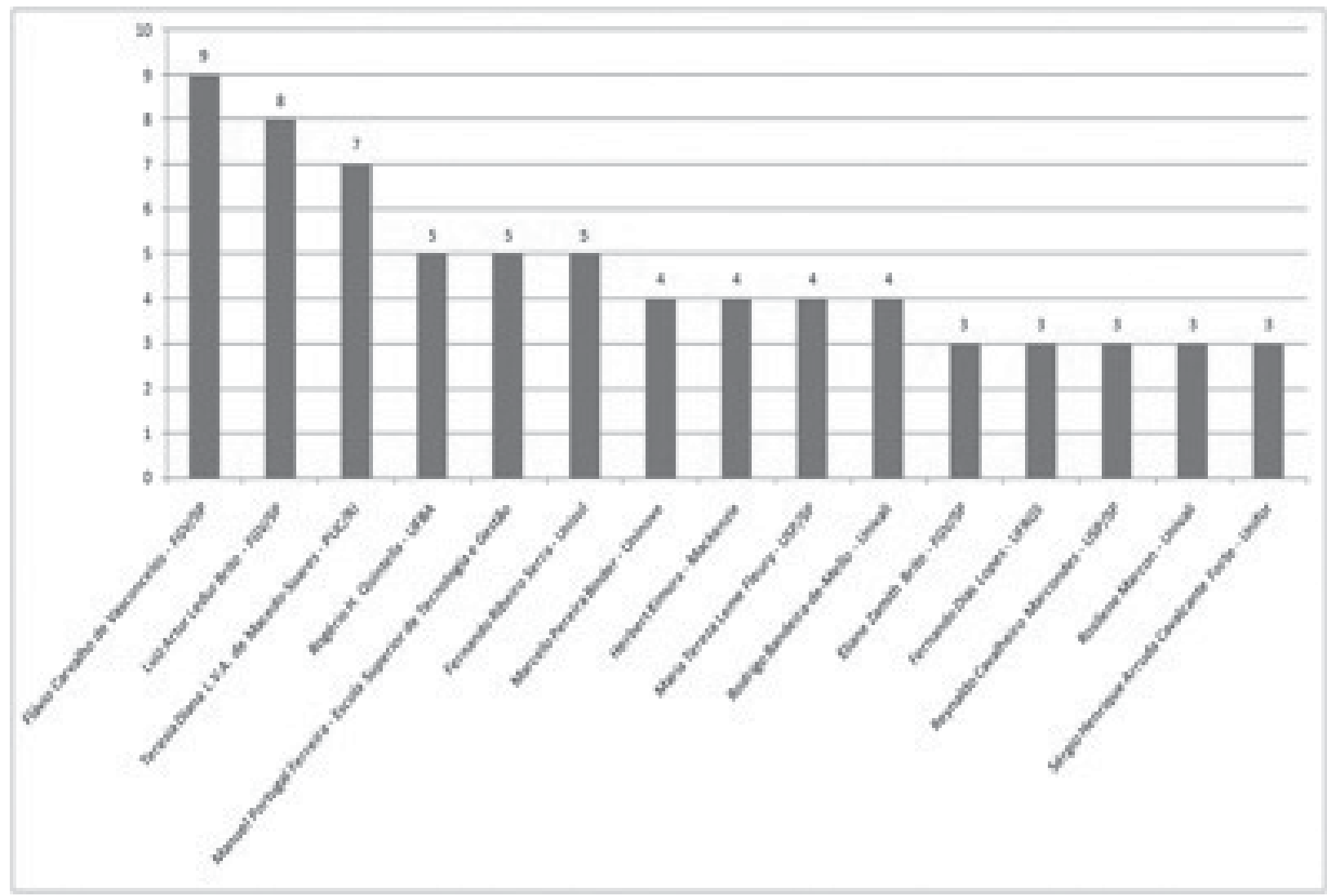

Gráfico 4: Publicação dos autores no período pesquisado

Fonte: Dados da pesquisa

Ainda cabe mencionar os autores Rogério $\mathrm{H}$. Quintella, Manuel Portugal Ferreira e Fernando Ribeiro Serra todos com cinco publicações. Já os autores, Marcelo Pereira Binder, Herbert Kimura, Maria Tereza Leme Fleury e Rodrigo Bandeira-de-Mello estão todos com quatro publicações e os autores: Eliane Zamith Brito, Fernando Dias Lopes, Reynaldo Cavalheiro Marcondes, Rosilene Marcon e Sérgio Henrique Arruda Cavalcante Forte todos com três artigos publicados sobre o tema. Walter e Silva (2008) corroboram em parte com a pesquisa ao afirmarem que Rodrigo Bandeira-de-Mello, Marcelo P. Binder, Sergio H. A. C. Forte publicaram, respectivamente, quatro, dois e dois artigos sobre o tema VBR entre os anos de 2002 e 2007, período da realização da pesquisa.

Em suma, dos 183 artigos investigados, somente 15 autores publicaram de três a nove artigos, ou seja, $6 \%$ do montante. Tal afirmação é corroborada pela Lei de Lotka, a qual enfatiza que poucos pesquisadores publicam muito e muitos pesquisadores publicam pouco, mostrando assim o grau de relevância destes poucos autores para com a temática ora investigada.
Constata-se também ao analisar o Gráfico 4, que a maioria dos autores é de Instituições de Ensino Superior (IES) do Sudeste do Brasil, ou seja: FGV/SP, FEA/USP, PUC/SP, PUC/RJ, Uninove e Mackenzie. Também aparecem autores das Instituições: UFRGS, Univali e Unisul da região Sul do País e os autores das IES: UFBA e Unifor, representantes da região Nordeste do Brasil. Autores Walter e Silva (2008), corroboram de maneira similar com os achados deste trabalho.

\subsubsection{Rede de Colaboração entre os Autores do Estudo}

Os Gráficos de 5 a 8 mostram a análise da rede social dos pesquisadores envolvidos neste estudo, ou seja, sua rede de colaboração e seu grau de centralidade. Optou-se pelo grau de centralidade por observar que é uma das propriedades de redes mais usadas, evidenciando aspectos relacionados com a importância $e$ a visibilidade do ator central da rede (CRUZ et al., 2011). Salienta-se que os laços indicam a integração entre os autores. 


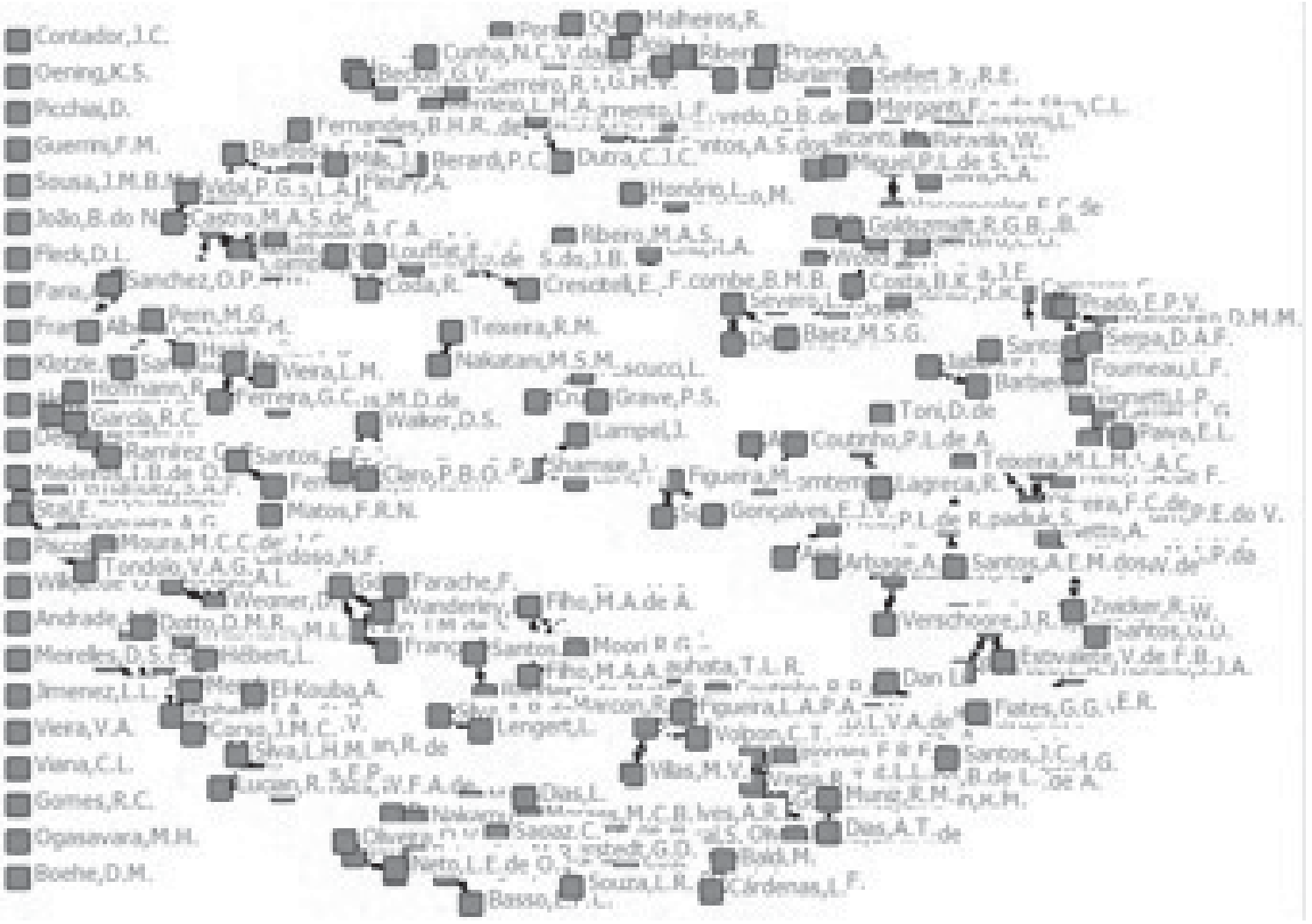

Gráfico 5: Rede de colaboração entre os autores do estudo

Fonte: Dados da pesquisa

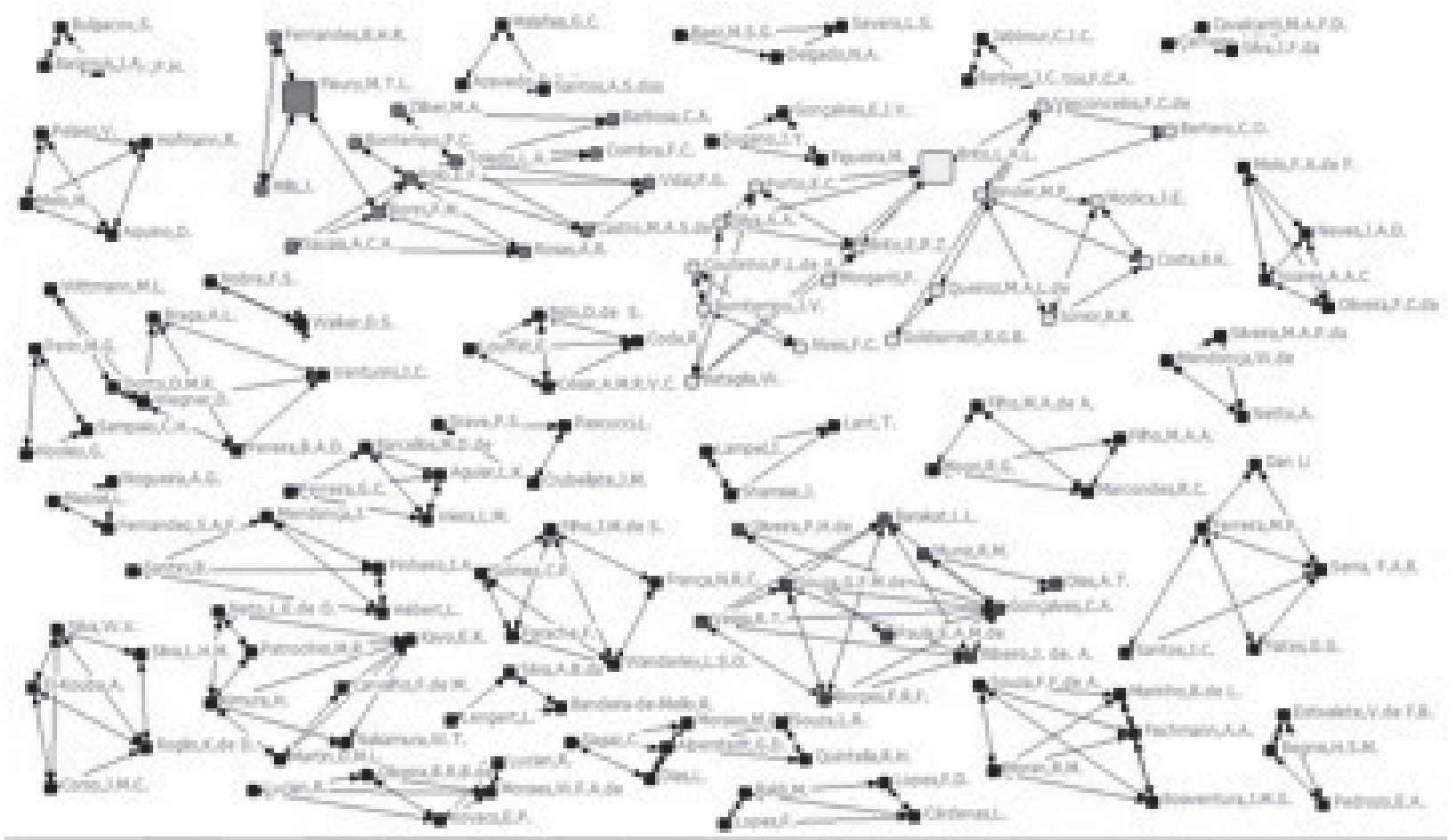

Gráfico 6: Principais redes de colaboração entre os autores do estudo

Fonte: Dados da pesquisa 
Ao observar o Gráfico 5, verifica-se que as relações de autoria entre os pesquisadores dos estudos são fragmentadas, concentrando-se em vários grupos de pesquisadores, porém, tal constatação não indica que não possa existir cooperação entre esses grupos, ou seja, entre a área ora investigada. Remete-se com isso a importância de diferentes pesquisadores para a evolução da temática ora estudada, possibilitando a posteriori formação de grupos de pesquisa, indicando que existe aproximação institucional entre os diversos autores evidenciado no Gráfico 5.

O Gráfico 6, complementa o Gráfico 5, ao evidenciar com maior transparência os principais grupos de colaboração entre os autores do estudo ora investigado.

As redes de cooperação que mais envolve pesquisadores são: Vasconcelos, F. C. de, Bertero, C. O., Modica, J. E., Costa, B.K., Júnior, R. R., Goldszmidt, R. G. B., Queiroz, M. A. L. de, Binder e o grupo dos autores: M. P., Bataglia, W., Alves, F. C., Bomtempo, J. V., Coutinho, P. L. de A., Morganti, F., Brito, E. P. Z., Silva, A. A., Porto, E. C. É interessante notar que o autor Brito, L. A. L. faz parte de ambos os grupos e é o principal elo de ligação entre os grupos.
Outros grupos se destacam, tendo Fleury, M. T. L. como a principal autora que vincula os dois grupos, são eles: Zilber, M. A., Barbosa, C. A., Coimbra, F. C., Vidal, P. G., Castro, M. A. S. de, Rosas, A. R., Sauaia, A. C. A., Borini, F. M., Polo, E. F., Toledo, L. A., e a dupla de autores, Fernandes, B. H. R. e Mills, J.

Ainda pode-se notar o grupo dos autores Oliveira, P. H. de, Barakat, L. L., Muniz, R. M., Dias, A. T., Gonçalves, C. A., Ribeiro, J. de A., Paula, E. A. M. de, Borges, F. R. F., Veiga, R. T. e Souza, G. F. M. de, dentre outros grupos.

Ao observa e analisar o Gráfico 06, constata-se que existe uma certa concentração geográfica da produção científica sobre a temática ora investigada dos pesquisadores da área. Tal fenômeno remete-se ao estudo de Lotka (1926) o qual descobriu que uma larga produção da literatura científica é produzida por pequenos grupos de autores. (GAZDA; QUANDT, 2010)

Nesse cenário remete-se ao grau de centralidade, que é entendido como o controle potencial do ator sobre outros que dele dependem para executar a interação (ROSSONI; FILHO, 2009). O gráfico 7, a seguir, aborda o grau de centralidade da rede de colaboração

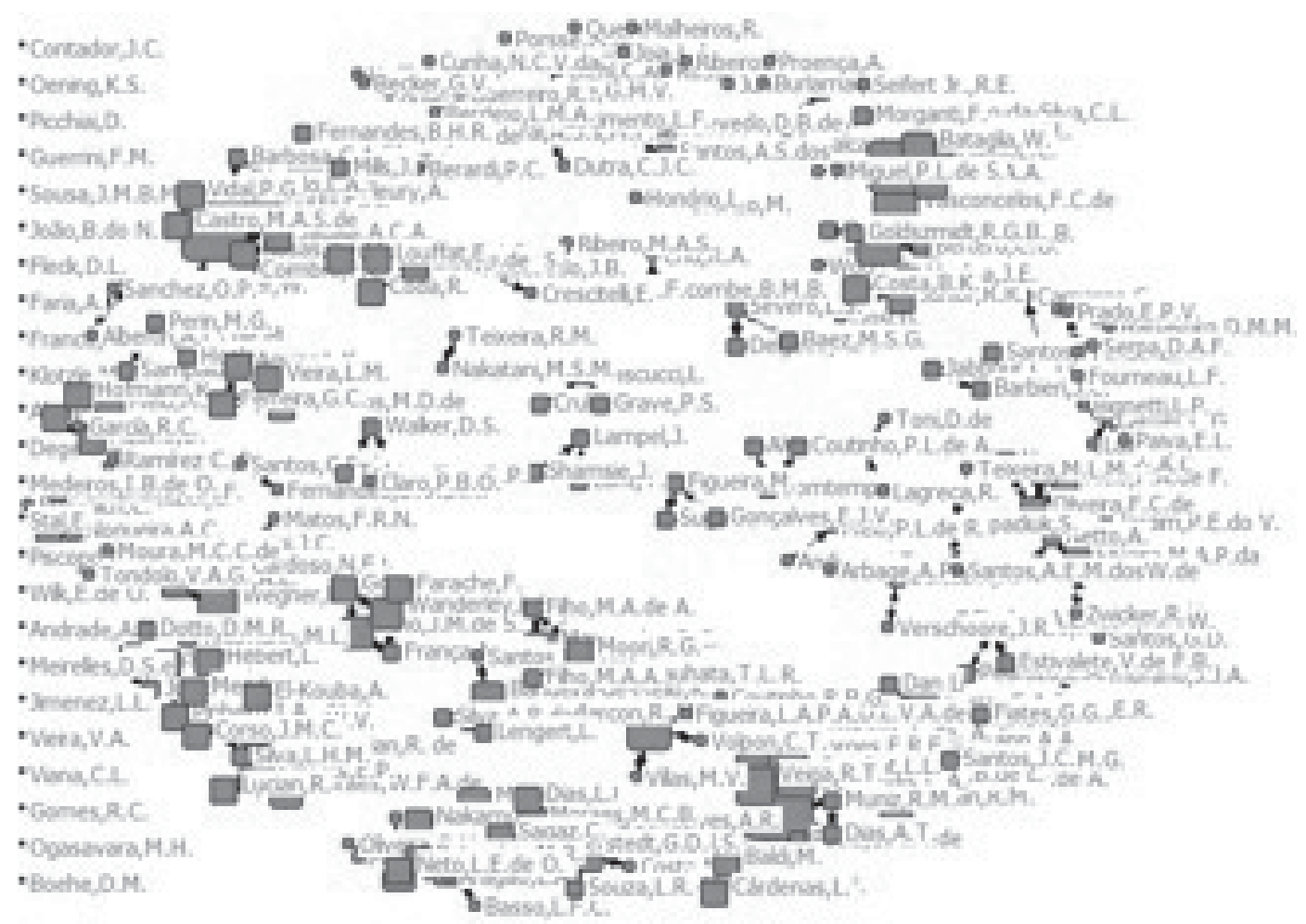

Gráfico 7: Grau de centralidade da rede de colaboração entre os autores do estudo

Fonte: Dados da pesquisa 


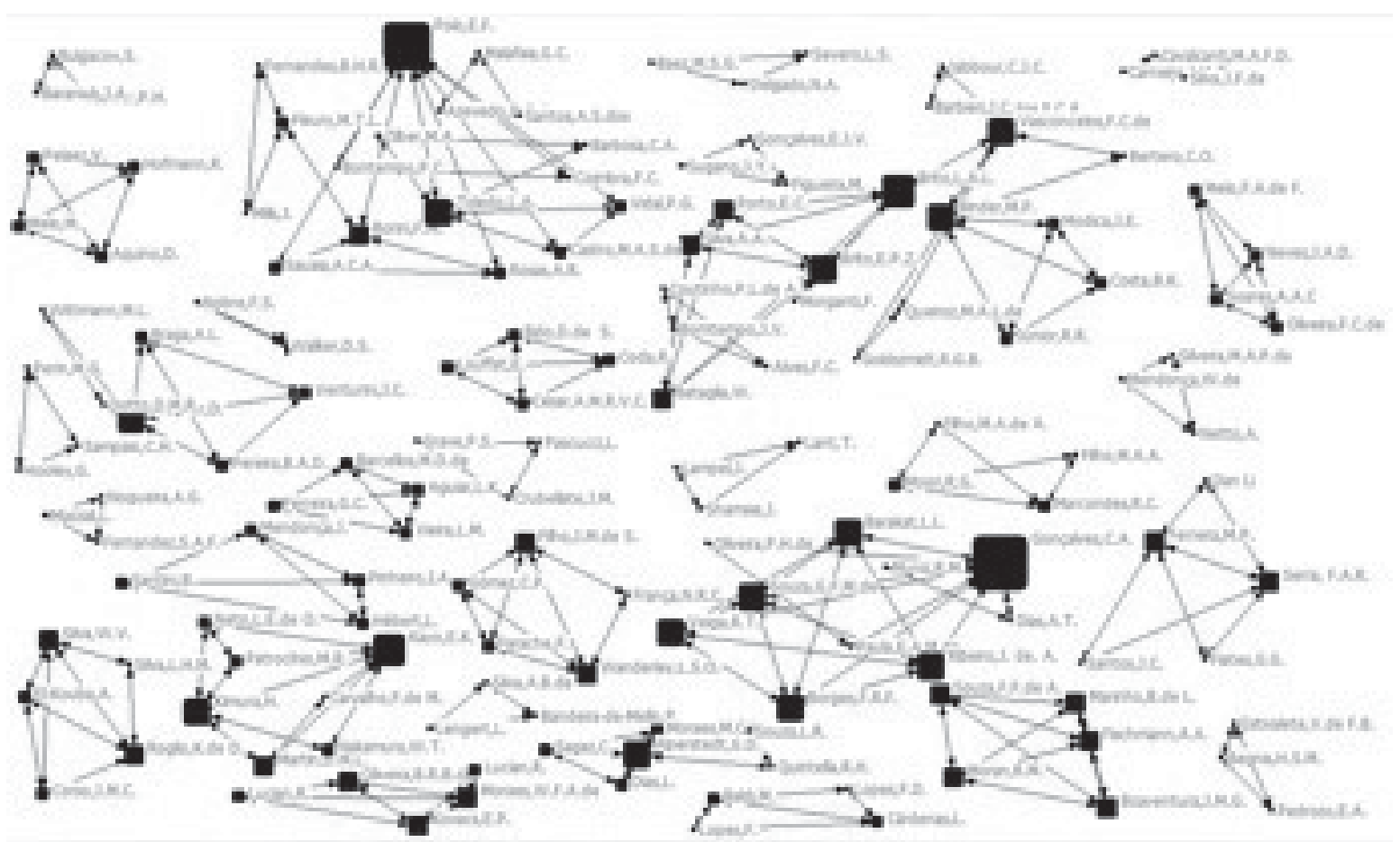

Gráfico 8: Grau de centralidade dos autores das principais redes de colaboração do estudo

Fonte: Dados da pesquisa

entre os autores do estudo. Nesse contexto, percebe-se que os dez principais autores centrais são: Luiz Artur Ledur Brito, Fernando Antonio Ribeiro Serra, Manuel Portugal Ferreira, Flávio Carvalho de Vasconcelos, Edison Fernandes Polo, Herbert Kimura, Carlos Alberto Gonçalves, Eduardo Kazuo Kayo, Eliane Pereira Zamith Brito e Luciano Augusto Toledo.

O Gráfico 8 complementa o Gráfico anterior, ao contemplar o grau de centralidade de cada autor de maneira respectiva das principais redes de colaboração.

Ao analisar as principais redes de colaboração, surgem alguns atores que se destacam em suas respectivas redes, que são: Luiz Artur Ledur Brito, Flávio Carvalho de Vasconcelos, Edison Fernandes Polo, Herbert Kimura, Carlos Alberto Gonçalves, Eduardo Kazuo Kayo, Eliane Pereira Zamith Brito e Luciano Augusto Toledo. Tal informação é similar ao que foi evidenciada no Gráfico 7, podendo sugerir certo grau de importância desses atores para com o tema ora estudado.

Tal resultado vai de encontro à densidade da rede de pesquisadores do referido estudo, a qual evidencia 0,0076, ou seja, $0,76 \%$ aproximado do potencial das relações estão sendo utilizadas. Entende-se com isso que, a rede social ora estudada, se configura com baixa interação. Tal cenário não reflete o ideal de se obter, pois, o essencial é ocorrer o maior intercâmbio possível, isto é, trocas de suporte sociais que são necessárias entre os pesquisadores.

O resultado evidenciado nos Gráficos 5 a 8 são corroborados de maneira similar em diversos estudos sociométricos (PARREIRA et al., 2006; ROSSONI et al., 2008; ROSSONI; HOCAYEN-DA-SILVA, 2008; NASCIMENTO; BEUREN, 2011) ao constatarem que a análise da centralidade e densidade dos pesquisadores do âmbito do stricto sensu são fortes e fracas respectivamente, ou seja, a centralidade da rede é ocupada por poucos pesquisadores e a densidade apresenta-se com ligações esparsas, podendo significar laços fracos na rede de pesquisadores. Os estudos bibliométricos dos autores: Bertero et al. (2003), Serra et al. (2008), Walter e Silva (2008) e Aragão et al. (2010) complementam tal afirmação.

\subsection{Referências mais Citadas}

A análise das referências bibliográficas é um fator importante para o desenvolvimento e a continuidade da ciência, pois impacta no reconhecimento de pesquisadores por seus pares; estabelece direitos de 
propriedade e de prioridade da publicação; e constitui importantes fontes de informação, mostrando com isso a literatura que é indispensável para o trabalho dos pesquisadores. (FORESTI, 1990)

Em suma, contemplará quais autores são mais citados em determinada temática (MURITIBA et al., 2010), contribuindo e proporcionando um norte para os pesquisadores experientes e para os iniciantes, impactando de maneira direta o crescimento de futuros trabalhos sobre o tema e contribuindo na disseminação e otimização do assunto ora investigado.

Internacionalmente, há programas, como o Journal Citation Reports, que fazem esse tipo de trabalho para os pesquisadores. No Brasil, na ausência de mecanismos do gênero, estudos de análise das referências vêm sendo executados a despeito da grande dificuldade operacional sem softwares específicos. (BIGNETTI; PAIVA, 2002)

O Gráfico 9 mostra a frequência de autores mais citados nos estudos de VBR nacionais. Ao analisar o Gráfico 9, constata-se que Michael Porter é o autor mais citado nas referências sobre a temática RBV no período analisado, ou seja, com 240 citações. Os autores Bignetti e Paiva (2002), Nagel e Löbler (2007) corroboram com a informação contemplada no gráfico anterior, por meio de seus respectivos estudos e achados que o autor Michael Porter é o mais citado dentre todos os autores de estratégia.

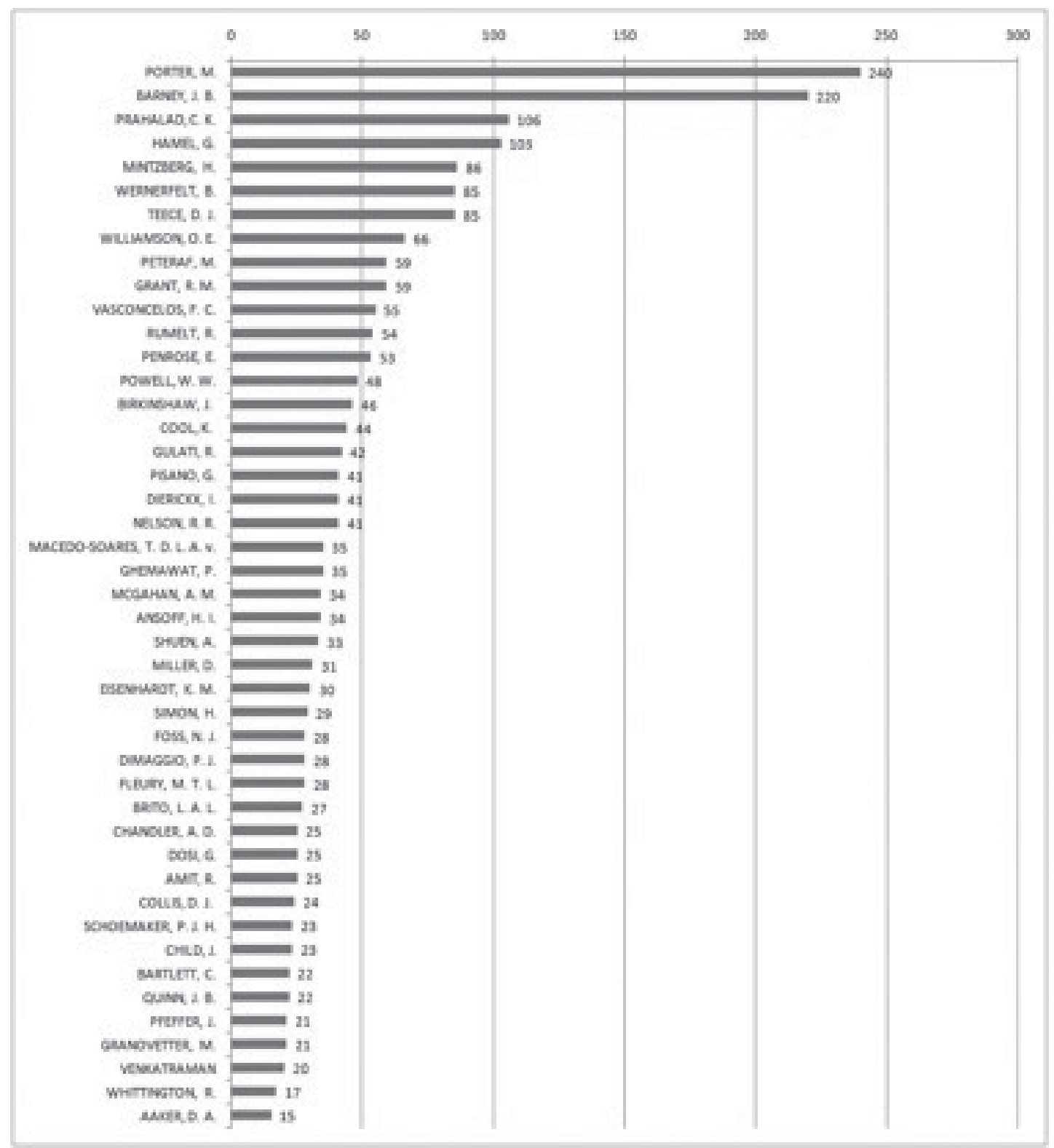

Gráfico 9: Autores mais citados no período pesquisado

Fonte: Dados da pesquisa 
Em seguida é contemplado o autor Jay Barney com 220 citações no total dos 183 artigos investigados. Michael Porter tem sido o autor mais citado e, por muitos, reverenciado em estratégia e ao considerar que a RBV é uma temática emergente da estratégia, remete-se a uma integração entre os trabalhos de Porter e a RBV. (SCHNEIDER et al., 2008)

O trabalho Cadeia de Valor de Porter (1985) foi utilizado no livro de estratégia de Barney, um dos autores fundamentais da abordagem emergente da estratégia, a RBV (SCHNEIDER et al., 2008). Durante a década de 1980, o foco principal da estratégia foi a integração entre o ambiente externo, a estratégia e a consequente performance das organizações, sendo praticamente desprezada a relação entre os recursos e competências da empresa e sua escolha como estratégia (CARNEIRO et al., 1997), surgindo assim publicações a posteriori sobre RBV em contraponto aos trabalhos de Porte.

Exemplo disso é o artigo seminal de Wernerfelt (1984), A resource-based view of the firm, que se utiliza do modelo das cinco forças de Porter como contraponto para sua análise da importância dos recursos como fonte de vantagem competitiva. Tais afirmações podem retratar o porque de Porter ser o autor mais referenciado nas citações sobre a temática VBR.

São contemplados também a seguir os autores que mais são citados nas referências dos 183 artigos pesquisados, são eles: C.K. Prahalad, Gary Hamel, Henry Mintzberg, Wernerfelt, B., Teece, D. J., Williamson, O. E., Peteraf, M., Grant, R. M., Vasconcelos, F. C., Rumelt, R., e Penrose, E., com 106, 103, 86, 85, 85, 66, 59, 59, 55, 54 e 53 citações, respectivamente. Ressalta-se que o autor Vasconcelos, além de ser o único pesquisador brasileiro entre os dez autores que são mais citados nos referenciais dos artigos, é também o que mais publica sobre o tema no âmbito (Gráfico 4). Os autores Aragão et al. (2010), Júnior et al. (2009), Coelho et al. (2009), Walter e Silva (2008) concordam com os achados de maneira similar.

Em suma, ao analisar o Gráfico $9 e$ as pesquisas anteriormente citadas no que se refere aos autores mais referenciados nas citações, verifica-se a presença e maioria absoluta de autores estrangeiros, principalmente na América do Norte, especialmente nos Estados Unidos. Constata-se também que o pesquisador Jay Barney que é vinculado a uma universidade america- na é apontado de maneira unânime como o principal nome na pesquisa em RBV no mundo, seguido pelos pesquisadores também bastante referenciados nas citações: Wernerfelt, Teece, Peteraf e Rumelt.

Cabe também evidenciar que os autores nacionais: Teresia Diana L.V.A. de Macedo-Soares, Maria Tereza Leme Fleury e Luiz Artur Ledur Brito, com 35, 28 e 27 citações respectivamente (Gráfico 9), também constam entre os autores que mais são citados nas referencias e que como ocorre com Vasconcelos são também um dos que mais publicam artigos sobre o tema investigado. Tal cenário mostra uma forte tendência de crescimento dos autores nacionais nas citações sobre o tema em questão.

Remetendo-se ao cenário acadêmico nacional, no que se refere à produtividade dos autores nacionais mais prolíferos, tal achado vai de encontro à Lei de Lotka, pois essa Lei parte da premissa de que, proporcionalmente, poucos autores publicam mais e, consequentemente, eles são mais citados do que muitos autores que publicam menos (MORETTI; CAMPANARIO, 2009). Ainda segundo os autores, tal constatação é visível em campos emergentes da ciência.

\subsection{Referências por Período}

A análise das referências abrange a quantidade de referências utilizadas nos 183 artigos investigados, permitindo assim identificar a evolução destas por década e um breve panorama das quantidades de obras que tratam sobre o tema de maneira direta ou indireta a partir do início do século XXI. O Gráfico 10 mostra que a partir da década de 1980 a 2000, houve um crescimento considerável das referências sobre a VBR, ou seja, aproximadamente $980 \%$. Como já antes evidenciado (Gráfico 1), uma provável explicação para tal otimização são publicações consolidadas e de forte impacto na construção da teoria da RBV que nortearam estes períodos e que de alguma forma influenciaram diretamente impulsionando o surgimento de novas pesquisas sobre o assunto no âmbito internacional $e$ também nacional.

Portanto, a partir dos estudos seminais de Edith Penrose (1959), criou-se a referência que deu origem a discussão sobre a temática. Ao longo da década de 1980 e no início da década de 1990, foram construídas as bases da abordagem da RBV com a contribuição de 
vários autores como Lippman e Rumelt (1982), Wernerfelt (1984), Rumelt (1984), Dierickx e Cool (1989), Barney (1991), Peteraf (1993), Hamel e Prahalad (1994), Teece et al. (1997).

E durante o início do século XXI, a temática da RBV continuou sendo consolidada mediantes as pesquisas de: Barney (2001) e Priem e Butler (2001), Barney et al. (2001) e Helfat e Peteraf (2003). Serra et al. (2008), ainda afirmam que os autores Ghemawat, Castanias e Helfat, Amit e Schoemaker, tiveram participação decisiva para tal impulsão mediante seus importantes trabalhos, consolidando e auxiliando o crescimento da temática da RBV durante as décadas de 1980 e 2000.

Ainda analisando o Gráfico 10, verifica-se que a maioria das referências investigadas nos 183 artigos da pesquisa é dos anos de 2000 a 2003, em particular o ano de 2001, totalizando 466 vezes. Tal fato pode ser explicado em virtude das primeiras pesquisas na década de 1980 e a consolidação delas no início da década de 1990 sobre a VBR, que impulsionaram e impactaram assim no surgimento de novas publicações que também se consolidaram e se tornaram importantes sobre o tema investigado (Gráfico 1). Tal afirmação é corroborada por Acedo, Barroso e Galan (2006), quando afirmam em sua pesquisa que houve um intenso aumento das publicações sobre RBT, entre os anos de 1992 a 2001.

\subsection{Abordagens Metodológicas}

Este item analisa as abordagens metodológicas preferidas pelos autores, de forma que se possa ter uma ideia da predominância de determinados métodos de pesquisa pelos pesquisadores do tema ora em estudo. Para fazer esta análise, foram utilizadas as informações fornecidas pelos próprios autores sobre o método que eles seguiram. Não cabe a este estudo julgar eventuais incongruências, já que se trata de artigos aprovados em revistas que possuem procedimentos de revisão (MURITIBA et al. 2010). Sampieri et al. (2006) afirmam que a pesquisa exploratória é realizada quando o objetivo é examinar um tema pouco estudado e a descritiva procura especificar as propriedades do fenômeno que se submete a análise. Sendo assim, ao analisar o Gráfico 11, verifica-se uma predominância de pesquisa exploratória e descritiva, podendo ser decorrente do fato de que o tema VBR ainda está em evolução no âmbito acadêmico nacional.

Quanto à abordagem, o Gráfico 11 evidencia que a maioria dos artigos investigados nas pesquisas adota o enfoque qualitativo, ou seja, 113. Os autores Aragão, Forte e Oliveira (2010), corroboram revelando mediante seu estudo que os artigos sobre o tema investigado é em sua maioria, qualitativo, ou seja, $63 \%$ do total. Bertero et al. (2003) constataram já em suba pesquisa uma carência de estudos de cunho quantitativo. Ainda segundo os autores, a predominância da pesquisa qualitativa não seguia na época a tendência da área de estratégia nos principais periódicos internacionais.

Porém, pode-se entender como fator positivo a evolução do número de artigos de natureza qualitativa (ARAGÃO et al., 2010), nos dias de hoje. Tal fato pode ser em decorrência da grande parte dos artigos pesquisados no período em questão, trabalharem a abordagem de Estudo de Caso. Walter et al. (2008), afirmam em seu estudo que quase $52 \%$ dos estudos de caso empregam técnicas de análise qualitativa. Nos úl-

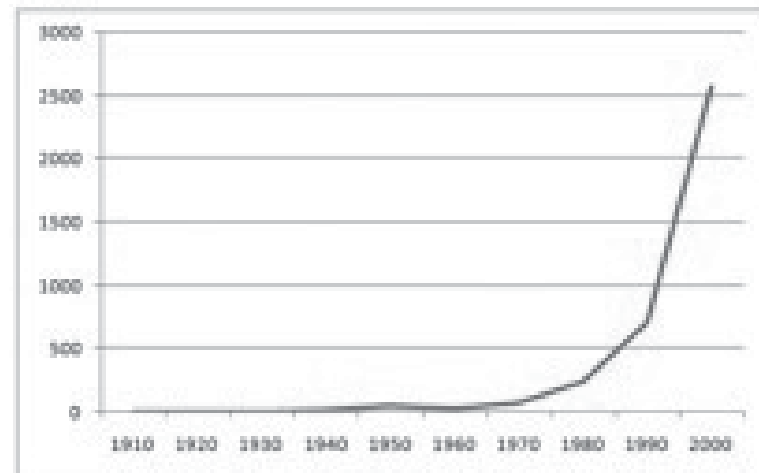

Gráfico 10: Idade das referências por década e por ano Fonte: Dados da pesquisa

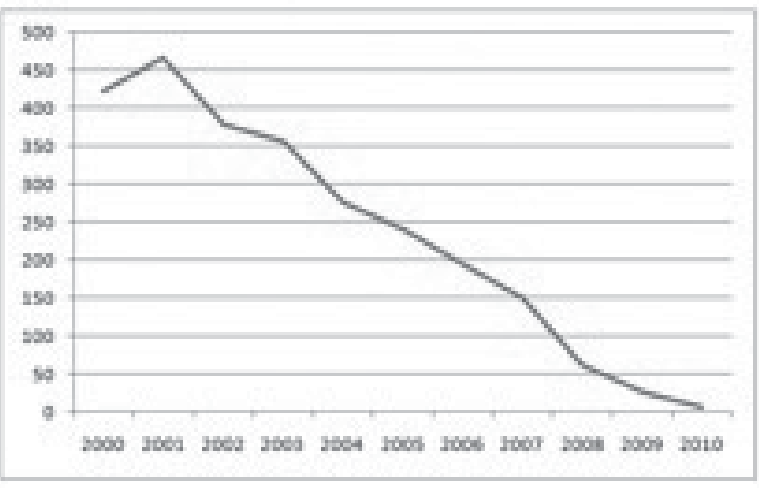




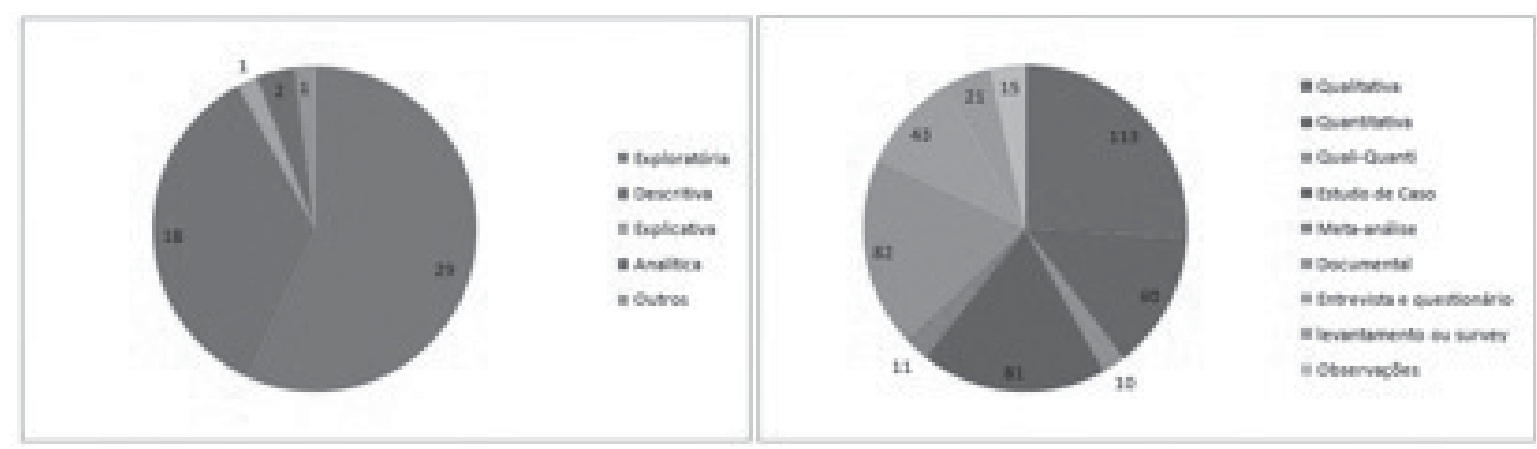

Gráfico 11: Métodos e tipologias de pesquisas utilizadas

Fonte: Dados da pesquisa

timos anos o estudo de caso tem sido uma abordagem amplamente utilizada nos estudos sociais, principalmente por pesquisadores que realizam investigações de cunho qualitativo (ARAGÃO et al., 2010), continuando assim, a ser um método de pesquisa marcante para a temática. (SERRA et al., 2008)

Tal afirmação é corroborada pelos autores Walter et al. (2008) e Walter e Silva (2008) ao afirmarem que o estudo de caso predomina nos artigos analisados em suas respectivas pesquisas. Walter e Silva (2008) também afirmam que a predominância do método de estudo de caso está diretamente relacionada à perspectiva da VBR, visto que ela propõe que cada firma possua características particulares que a diferem das demais. Além disso, tal método tende a facilitar o trabalho em virtude das características que se fazem específicas e distintas de cada empresa.

Em suma, a análise dos métodos de pesquisa dos artigos, mostra que, quanto aos objetivos, há uma opção maior dos autores para estudo de caso, entrevista e ou questionário, documental, exploratória e descritiva. Afirmação corroborada pelos autores Aragão et al. (2010) e Walter et al. (2008). Isso sugere mais uma confirmação ou uma busca de consolidação da temática da RBV, por entender que tal tema é emergente na literatura acadêmica nacional.

Quanto à abordagem, com maior opção se apresenta a pesquisa qualitativa, em $62 \%$ dos artigos investigados. Entende-se que tal método busca mediante os estudos de caso (simples ou múltiplos), por exemplo, a confirmação de resultados, apesar de que alguns dos estudos investigados se utilizarem também da abordagem quantitativa, ou seja, $33 \%$ e outra pequena parte dos estudos a abordagem quali-quanti, ou seja, $5 \%$ para otimizar suas analises. Tais percentuais são corroborados de maneira similar pela pesquisa dos autores Aragão et al. (2010), ao afirmarem que as abordagens: qualitativa, quantitativa e quali-quanti têm predominância de 63\%, 27\% e 10\% do total dos trabalhos investigados.

\section{Considerações Finais}

O presente trabalho investigou o perfil das pesquisas e a evolução do tema VBR nos artigos publicados nas Revistas classificadas no Qualis B5 a A1 da Capes, no período de 2000 a 2010. Para tanto, efetuou-se uma análise bibliométrica em uma amostra de 183 artigos. Foi priorizado na pesquisa o foco nos seguintes critérios: (I) evolução do tema e periódicos de destaque; (II) características de autoria; (III) autores com maior produção neste tema; (IV) referências mais citadas; (V) referências por período; (VI) abordagens metodológicas.

Apesar de existirem algumas centenas de artigos empíricos que derivam das proposições teóricas da RBV (ACEDO et al., 2006), acredita-se que o referido trabalho tenha possibilitado algumas contribuições fundamentais como a resposta a pergunta apresentada na introdução, ao apresentar o perfil das pesquisas e a evolução do tema RBV no âmbito nacional.

Diante do exposto, a referida pesquisa constatou pouca ocorrência de estudos relacionados à temática nos anos de 2000 e 2001. Observou-se que mais da metade, ou seja, $56,83 \%$ dos artigos publicados estão contemplados nas revistas: RAC, BAR, RAI, BASE e RAE.Verificou-se que os artigos individuais ocorrem em menor número em comparação com os demais, podendo ser um indicativo da existência de grupos de pesquisa sobre a temática. 
Contemplam-se os autores Vasconcelos, F. C. de., Brito, L. A. L. e Macedo-Soares, T. D. L. V. A. de. como os autores que mais publicam artigos sobre VBR como tema central ou não no período analisado, com nove, oito e sete artigos publicados respectivamente. Nesse cenário, observou-se que os autores Luiz Artur Ledur Brito, Fernando Antonio Ribeiro Serra, Manuel Portugal Ferreira, Flávio Carvalho de Vasconcelos, Edison Fernandes Polo, Herbert Kimura, Carlos Alberto Gonçalves, Eduardo Kazuo Kayo, Eliane Pereira Zamith Brito e Luciano Augusto Toledo, são os principais atores centrais da rede de colaboração macro e micro sobre a temática "objeto de estudo". Desses pesquisadores destacam-se os mais prolíferos na área, ou seja, Vasconcelos, F. C. de. e Brito, L. A. L.

Constatou-se que Michael Porter é o autor mais citado nas referências sobre a temática da RBV no período analisado, ou seja, com 240 citações. Em seguida é contemplado o autor Jay Barney com 220 citações no total dos 183 artigos investigados. Evidenciou-se que a partir de 1980 a 2000 houve um crescimento considerável das referências sobre a VBR, ou seja, aproximadamente $980 \%$.

Constatou-se que a análise dos métodos de pesquisa dos artigos mostra que, quanto aos objetivos, há uma opção maior dos autores para estudo de caso, entrevista e ou questionário, documental, exploratória e descritiva. Quanto à abordagem, com maior opção se apresenta a qualitativa, que busca mediante os estudos de caso (simples ou múltiplos), por exemplo, a confirmação de resultados, apesar de que alguns dos estudos investigados se utilizarem também da abordagem quantitativa ou quali-quanti, para otimizar suas análises.

Concluiu-se neste estudo, de maneira geral, um perfil macro das publicações e da evolução da VBR, analisando aspectos sobre o tema com o intuito de nortear e efetivamente contribuir com a melhoria e fomento dos artigos sobre a temática no meio acadêmico. Como limitação do estudo, ressalta-se que a amostra restringiu-se às publicações das Revistas Qualis B5 a A1 da área de Administração, deixando de considerar as áreas de Economia, Contabilidade e Finanças, que poderiam acrescentar mais informações ao que foi levantado. Sugere-se, para futuros estudos uma análise dos conteúdos (revisão teórica) abordados nos trabalhos investigados, isso proporcionará evidenciar, mediante comparação, de como a temática VBR é vista no Mundo e na visão dos autores; e uma análise mais aprofundada de redes sociais utilizando para isso de outros indicadores de redes.

\section{REFERÊNCIAS}

ACEDO, F. J. et al. The resource-based theory:

dissemination and main trends. Strategic Management Journal, USA, n. 27, p. 621-636, 2006.

ALVARADO, R. U. A bibliometria no Brasil. Ciência da Informação, Brasília, v. 13, n. 2, p. 91-105, 1984.

ARAGÃO, L. A. et al. Visão baseada em recursos e capacidades dinâmicas no contexto brasileiro: a produção e a evolução acadêmica em dez anos de contribuições.

Revista Eletrônica de Administração, Porto Alegre, v. 16, n. 2, p. 1-24, 2010.

ARAÚJO, C. A. Bibliometria: evolução histórica e questões atuais. Em Questão, Porto Alegre, v. 12, n. 1, p. 11-32, 2006.

BARNEY, J. Firm resources and sustained competitive advantage. Journal of Management, USA, v. 17, n. 1, p. 99-120, 1991.

BARNEY, J. B. Is the resource-based "view" a useful perspective for strategic management research? Yes. Academy of Management Review, USA, v. 26, n. 1, p. 41-56, 2001.

BARNEY, J. et al. The resource-based view of the firm: ten years after 1991. Journal of Managemet, USA, v. 27, p. 625-641, 2001.

BERTERO, C. O. et al. Estratégia empresarial: a produção científica brasileira entre 1991 e 2002. Revista de

Administração de Empresas, São Paulo, v. 43, n. 4, p. $48-62,2003$.

BIGNETTI, L. P.; PAIVA, E. L. Ora (direis) ouvir estrelas! Estudo das citações de autores de estratégia na produção acadêmica brasileira. Revista de Administração

Contemporânea, São Paulo, v. 6, p. 105-125, 2002. 
BINDER, M. P. Rede de recurso: um modelo desenvolvido a partir do caso Gol Linhas Aéreas. Revista de

Administração e Inovação, São Paulo, v. 6, n. 2, p. 28-43, 2009.

BOYD, B. K. CFO duality and firm performance: a contingency model. Strategic Management Journal, USA, v. 16, p. 301-312, 1995.

BRITO, L. A. L.; VASCONCELOS, F. C. de. A heterogeneidade do desempenho, suas causas e o conceito de vantagem competitiva: proposta de uma métrica. Revista de Administração Contemporânea, São Paulo, Edição Especial, p. 107-129, 2004.

BUFREM, L.; PRATES, Y. O saber científico registrado e as práticas de mensuração da informação. Ciência da Informação, Brasília, v. 34, n. 2, p. 9-25, 2005.

CAPES - Coordenação de Aperfeiçoamento de Pessoal de Nível Superior. Revistas Qualis. [2011]. Disponível em: <http:/qualis.capes.gov.br/webqualis/ ConsultaListaCompletaPeriodicos.faces > . Acesso em: 23 abr. 2011.

CAPES. Coordenação de Aperfeiçoamento de Pessoal de Nível Superior. História e Missão. [2006]. Disponível em: <http://www.capes.gov.br/sobre-a-capes/historia-emissao >. Acesso em: 15 set. 2012.

CARDOSO, R. L. et al. Pesquisa cientifica em contabilidade entre 1990 e 2003. Revista de

Administração de Empresas, São Paulo, v. 45, n. 2, p. 34-45, 2005.

CARNEIRO, J. M. T. et al. Porter revisitado: análise crítica da tipologia estratégica do mestre. Revista de Administração Contemporânea, São Paulo, v. 1, n. 3, set./dez., 1997.

COELHO, A. L. de. A. L. et al. A produção científica direcionada a visão baseada em recursos (resource-based view-rbv) no Brasil e no exterior. Revista Brasileira de Docência, Ensino e Pesquisa em Administração, Cristalina, v. 1, n. 2, p. 177-207, 2009.

COOPER, H. M.; LINDSAY, J. J. Research synthesis and meta-analysis. In: L. Bickman; D. J. Rog; Handbook of applied social research methods. Thousand Oaks, CA: Sage Publications, 1998. p. 315-342.
CRUZ, A. P. C. da. et al. Perfil das redes de cooperação científica: congresso USP de controladoria e contabilidade - 2001 a 2009. Revista Contabilidade \& Finanças, São Paulo, v. 22, n. 55, p. 64-87, 2011.

DIERICKX, I.; COOL, K. Asset stock accumulation and sustainability of competitive advantage. Management Science, USA, v. 35, n. 12, p. 1.504-1.511, 1989.

FLEURY, M. T. L.; FLEURY, A. Construindo o conceito de competência. Revista de Administração

Contemporânea, São Paulo, Edição Especial, p. 183196, 2001.

FORESTI, N. A. B. Contribuição das revistas brasileiras de biblioteconomia e ciência da informação enquanto fonte de referência para a pesquisa. Ciência da Informação, Brasília, v. 19, n. 1, p. 53-71, 1990.

GAZDA, E.; QUANDT, C. O. Colaboração interinstitucional em pesquisa no Brasil: tendências em artigos na área de gestão da inovação. RAE Eletrônica, São Paulo, v. 9, n. 2, 2010.

HAMEL, G.; PRAHALAD, C. K. Competing for the future. Boston: Harvard Business School, 1994.

HELFAT, C. E.; PETERAF, M. A. The dynamic resourcebased view: capability lifecycles. Strategic Management Journal USA, v. 24, p. 997-1.010, 2003.

JENSEN, M.; MECKLING, W. Theory of the firm: managerial behavior, agency costs and ownership structure. Journal of Financial Economics, USA, v. 3, p. 1-77, 1976.

JÚNIOR, A. F. S. et al. A contribuição da visão baseada em recursos para a pesquisa em contabilidade gerencial: uma análise bibliométrica. Revista de Informação Contábil, Recife, v, 3, n. 3, p. 117-142, jul-set/2009.

LEITE FILHO, Geraldo A. Padrões de produtividade de autores em periódicos de congressos na área de contabilidade no Brasil: um estudo bibliométrico. In: CONGRESSO USP CONTROLADORIA E CONTABILIDADE. Anais Eletrônicos... Congresso USP de Controladoria e Contabilidade, 2006. Disponível em: <http://www.congressousp.fipecafi.org > . Acesso em: 25 abr. 2011. 
Henrique César Melo Ribeiro • Benny Kramer Costa • Sérgio Nunes Muritiba • Geraldo Cardoso de Oliveira Neto

LEVITT, B.; MARCH, J. Organizational learning. Annual Review of Sociology, v. 14, p. 319-340, 1988.

LIPPMAN, S. A.; RUMELT, R. P. Uncertain imitability. Bell Journal of Economics, USA, v. 13, n. 2, p. 418438, 1982.

LOPES, A. B.; REINHARD, N. Vantagens competitivas na distribuição de informações financeiras em tempo real: uma análise baseada em recursos. Revista de Administração da USP, São Paulo, v. 33, n. 2, p. 6978, 1998.

MINTZBERG, H. et al. Safári de estratégia: um roteiro pela selva do planejamento estratégico. Porto Alegre: Bookman, 2000.

MORETTI, S. L. A.; CAMPANARIO, M. de A. A produção intelectual brasileira em responsabilidade social empresarial - RSE sob a ótica da bibliometria. Revista de Administração Contemporânea, São Paulo, v. 13, Edição Especial, 2009.

MURITIBA, S. N. et al. Governança corporativa no Brasil: uma análise bibliométrica das publicações dos últimos doze anos. In: SEMINÁRIO EM ADMINISTRAÇÃO. XIII Semead. Anais Eletrônicos... São Paulo: Semead, 2010. Disponível em: <http://www.ead.fea.usp.br/ semead/13semead/resultado/trabalhosPDF/887.pdf $>$. Acesso em: 8 maio 2011.

NASCIMENTO, S. do.; BEUREN, I. M. Redes sociais na produção científica dos programas de pós-graduação de ciências contábeis do Brasil. Revista de Administração Contemporânea, São Paulo, v. 15, n. 1, p. 47-66, 2011.

NAGEL, M. A. de B.; LÖBLER, M. L. Aplicação da técnica de análise de citações como um instrumento de avaliação da biblioteca setorial do CCSH/UFSM. Sociais e Humanas, Santa Maria, v. 20, n. spe, p. 239-250, 2007.

NASSIF, V. M. J.; HANASHIRO, D. M. M. A competitividade das universidades particulares à luz de uma visão baseada em recursos. Revista de Administração da Mackenzie, São Paulo, v. 3, n. 1, p. 95-114, 2002.
NEDERHOF, A. J. Bibliometric monitoring of research performance in the social sciences and the humanities: $A$ review. Scientometrics, USA, v. 66, n. 1, p. 81-100, 2006.

NELSON, R.; WINTER, S. An evolutionary theory of economic change. Cambridge: Harward University Press, 1982.

PENROSE, E. The theory of the growth of the firm. Oxford: Oxford University Press, 1959.

PETERAF, M. A. The cornerstones of competitive advantage: a resource-based view. Strategic Management Journal, USA, v. 14, n. 3, p. 179-191, 1993.

PARREIRAS, F. S. et al. RedeCI: colaboração e produção científica em ciência da informação no Brasil.

Perspectiva em Ciência da Informação, Belo Horizonte, v. 11, n. 3, p. 302-317, 2006.

PINTO, A. L. et al. Visibilidade e monitoramento científico na área nuclear e ciências relacionadas: uma perspectiva a partir da produtividade do IPEN-CNEN/SP. Perspectivas em Ciência da Informação, Belo Horizonte, v. 15, n. 2, p. 198-218, 2010.

PORTER, M. E. Competitive strategy: techniques for analyzing industries and competitors. New York: Free Press, 1980.

PORTER, M. E. Competitive advantage: creating and sustaining superior performance. New York: The Free Press, 1985.

PRIEM, R.L.; BUTLER, J.E. Is the resource-based view a useful perspective for strategic management research? The Academy of Management Review, USA, v. 26, n. 1, p. 22-40, 2001.

QUONIAM, L. et al. Inteligência obtida pela aplicação de data mining em base de teses francesas sobre o Brasil. Ciência da Informação, Brasilia, v. 30, n. 2, p. 20-28, 2001.

RIVERA, E. B. B. Resource based view e o neoinstitucionalismo na análise organizacional para a promoção da vantagem competitiva sustentável. In: ASSOCIAÇÃO NACIONAL DE PÓS-GRADUAÇÃO E PESQUISA EM ADMINISTRAÇÃO. Anais Eletrônicos... Brasília/DF: XXV Simpósio de Gestão da Inovação Tecnológica, 2008. Disponível em: <http://www.anpad. org.br>. Acesso em: 23 abr. 2011. 
ROSSONI, L.; FILHO, E. R. G. Cooperação entre programas de pós-graduação em administração no Brasil: evidências estruturais em quatro áreas temáticas. Revista de Administração Contemporânea, São Paulo, v. 13, n. 3, p. 366-390, 2009.

ROSSONI, L. et al. Aspectos estruturais da cooperação entre pesquisadores no campo de administração pública e gestão social: análise das redes entre instituições no Brasil. Revista de Administração Pública, São Paulo, v. 42, n. 6, p. 1041-1067, 2008.

- Cooperação entre pesquisadores da área de administração da informação: evidências estruturais de fragmentação das relações no campo científico. Revista de Administração da USP, São Paulo, v. 43, n. 2, p. 138-151, 2008.

RUMELT, R. P. Towards a strategic theory of the firm. In: LAMB, R. B. (Ed.). Competitive strategic management. Upper Sadler River: Prentice Hall, p. 95-117, 1984.

SCHNEIDER, A. B. et al. Michael Porter 30 anos depois de estratégia competitiva: influência do autor nos trabalhos brasileiros em estratégia - estudo bibliométrico em trabalhos dos últimos dez anos do ENANPAD. IPL - Instituto

Politécnico de Leitura. Working paper séries, 2008.

SERRA, F. A. R. et al. Evolução da pesquisa brasileira em resource-based view (rbv): estudo dos enanpad na área de estratégia entre 1997-2006. IPL - Instituto Politécnico de Leitura - Working paper séries, 2007.

SERRA, F. A. R. et al. Evolução da pesquisa em RBV: um estudo dos últimos enanpad's. Revista Brasileira

Estratégia, Curitiba, v. 1, n. 1, p. 39-56, 2008.

SINGLETON, R. A.; STRAITS, B. C. Approaches to social research. New York: Oxford University Press, 1999.

SUBRAMANYAM, K. Bibliometric studies of research collaboration: a review. Journal of Information

Science, USA, v. 6, n. 1, p. 33, CILIP, 1983.

TEECE, D. J. et al. Dynamic capabilities and strategic management. Strategic Management Journal, USA, v. 18, n. 7, p. 509-533, 1997.

TESTA, J. A base de dados ISI e seu processo de seleção de revistas. Ciência da Informação, Brasília, v. 27, n. 2, p. 233-235, 1998.
TONDOLO, V. A. G.; BITENCOURT, C. C. Uma perspective baseada em recursos no agronegócio cooperativo. São Paulo: RAE-eletrônica, São Paulo, v. 7, n. 1, 2008.

VANTI, N. A. P. Da bibliometria à webometria: uma exploração conceitual dos mecanismos utilizados para medir o registro da informação e a difusão do conhecimento. Ciência da Informação, Brasília, v. 31, n. 2, p. 152-162, 2002.

VASCONCELOS, F. C.; CYRINO, A. B. Vantagem competitiva: os modelos teóricos atuais e a convergência entre estratégia e teoria organizacional. Revista de Administração de Empresas, São Paulo, v. 40, n. 4, p. 20-37, 2000.

WALTER, S. A.; SILVA, E. D. da. Visão baseada em recursos: um estudo bibliométrico e de redes sociais da produção científica da área de estratégia do enanpad 1997-2007. In: ASSOCIAÇÃO NACIONAL DE PÓSGRADUAÇÃO E PESQUISA EM ADMINISTRAÇÃO. XXXII EnANPAD. Anais Eletrônicos... Rio de Janeiro: ANPAD, 2008. Disponível em: < http://www.anpad.org. br/>. Acesso em: 11 maio 2011.

WALTER, S. A. et al. Visão baseada em recursos: uma análise dos delineamentos metodológicos e da maturidade dessa abordagem na área de estratégia do enanpad 1997-2007. In: ASSOCIAÇÃO NACIONAL DE PÓS-GRADUAÇÃO E PESQUISA EM ADMINISTRAÇÃO. XXXII EnANPAD. Anais Eletrônicos... Rio de Janeiro: ANPAD, 2008. Disponível em: < http://www.anpad.org. br/>. Acesso em: 11 maio 2011.

WERNERFELT, B. A resource-based view of the firm. Strategic Management Journal, USA, v. 5, n. 2, p. 171-180, 1984.

WILK, E. de O. O uso de uma abordagem "resource based view" na formulação de estratégias, o caso do setor vitivinícola da serra gaúcha. Revista Eletrônica de Administração, Rio Grande do Sul, v. 7, n. 2, 2001.

WILLIAMSON, O. The economic institutions of capitalism: firms, markets, relational contracting. New York: The Free Press, 1985.

ZUCKER, L. Institutional theories of organization. Annual Review of Sociology, USA, v. 13, p. 443-464, 1987. 